\title{
Recombinant Antigen of Type 2 Porcine Reproductive and Respiratory Syndrome Virus (PRRSV-2) Promotes M1 Repolarization of Porcine Alveolar Macrophages and Th1 Type Response
}

\author{
Rika Wahyuningtyas ${ }^{1,2} \mathbb{D}$, Yin-Siew Lai ${ }^{1} \mathbb{D}$, Mei-Li Wu ${ }^{1,3}$, Hsin-Wei Chen ${ }^{4,5,6} \mathbb{C}$, Wen-Bin Chung ${ }^{2}$, \\ Hso-Chi Chaung ${ }^{1,2,7, *}$ and Ko-Tung Chang ${ }^{1,7,8, * \mathbb{D}}$
}

check for updates

Citation: Wahyuningtyas, R.; Lai, Y.-S.; Wu, M.-L.; Chen, H.-W.; Chung, W.-B.; Chaung, H.-C.; Chang, K.-T. Recombinant Antigen of Type 2 Porcine Reproductive and Respiratory Syndrome Virus (PRRSV-2) Promotes M1 Repolarization of Porcine Alveolar Macrophages and Th1 Type Response. Vaccines 2021, 9, 1009. https:// doi.org/10.3390/vaccines9091009

Academic Editors: Hiep L. X. Vu and Asit Pattnaik

Received: 22 June 2021

Accepted: 7 September 2021

Published: 10 September 2021

Publisher's Note: MDPI stays neutral with regard to jurisdictional claims in published maps and institutional affiliations.

Copyright: (c) 2021 by the authors. Licensee MDPI, Basel, Switzerland. This article is an open access article distributed under the terms and conditions of the Creative Commons Attribution (CC BY) license (https:/ / creativecommons.org/licenses/by/ $4.0 /)$.
1 Research Centre for Animal Biologics, National Pingtung University of Science and Technology, Neipu, Pingtung 912, Taiwan; rikawahyurizky@gmail.com (R.W.); rindy.0802@gmail.com (Y.-S.L.); mlwu@mail.npust.edu.tw (M.-L.W.)

2 Department of Veterinary Medicine, National Pingtung University of Science and Technology, Neipu, Pingtung 912, Taiwan; wbchung@mail.npust.edu.tw

3 Department of Food Science, National Pingtung University of Science and Technology, Neipu, Pingtung 912, Taiwan

4 National Institute of Infectious Diseases and Vaccinology, National Health Research Institutes, Miaoli 350, Taiwan; chenhw@nhri.org.tw

5 Graduate Institute of Biomedical Sciences, China Medical University, Taichung 400, Taiwan

6 Graduate Institute of Medicine, College of Medicine, Kaohsiung Medical University, Kaohsiung 800, Taiwan

7 Flow Cytometry Center, Precision Instruments Center, National Pingtung University of Science and Technology, Neipu, Pingtung 912, Taiwan

8 Department of Biological Science and Technology, National Pingtung University of Science and Technology, Neipu, Pingtung 912, Taiwan

* Correspondence: hcchaung@mail.npust.edu.tw (H.-C.C.); kotungc@mail.npust.edu.tw (K.-T.C.)

\begin{abstract}
The polarization status of porcine alveolar macrophages (PAMs) determines the infectivity of porcine reproductive and respiratory syndrome virus (PRRSV). PRRSV infection skews macrophage polarization toward an M2 phenotype, followed by T-cells inactivation. CD163, one of the scavenger receptors of M2 macrophages, has been described as a putative receptor for PRRSV. In this study, we examined two types of PRRSV-2-derived recombinant antigens, A1 (g6Ld10T) and A2 (lipo-M5Nt), for their ability to mediate PAM polarization and T helper (Th1) response. A1 and A2 were composed of different combination of ORF5, ORF6, and ORF7 in full or partial length. To enhance the adaptive immunity, they were conjugated with T cells epitopes or lipidated elements, respectively. Our results showed that $\mathrm{CD} 163^{+}$expression on PAMs significantly decreased after being challenged with A1 but not A2, followed by a significant increase in pro-inflammatory genes (TNF- $\alpha, I L-6$, and $I L-12$ ). In addition, next generation sequencing (NGS) data show an increase in T-cell receptor signaling in PAMs challenged with A1. Using a co-culture system, PAMs challenged with $\mathrm{A} 1$ can induce Th1 activation by boosting IFN- $\gamma$ and $I L-12$ secretion and TNF- $\alpha$ expression. In terms of innate and T-cell-mediated immunity, we conclude that A1 is regarded as a potential vaccine for immunization against PRRSV infection due to its ability to reverse the polarization status of PAMs toward pro-inflammatory phenotypes, which in turn reduces CD163 expression for viral entry and increases immunomodulation for Th1-type response.
\end{abstract}

Keywords: PAMs; CD163; PRRSV; M1; M2; Th1

\section{Introduction}

Porcine reproductive and respiratory syndrome virus (PRRSV) causes severe respiratory and reproductive disease in swine worldwide. According to the current genetic analysis by the International Committee on Taxonomy of Viruses (ICTV) PRRSV has been 
reclassified to the Betaarterivirus genus, belonging to the order Nidovirales and the Arteriviridae family. Type 1 (European) and type 2 (American) are the two main genotypes of PRRSV, which have been classified into two distinct virus species (namely Betaarterivirus suid 1 and Betaarterivirus suid 2) [1]. European PRRSV has further divided into three subtypes, pan-European subtype 1 and East European subtypes 2 and 3, and at least nine different genetic lineages of North American PRRSV have been classified [2]. It consists of an enveloped virus, positive single-stranded RNA and is encapsulated in nucleocapsid proteins containing 11 open reading frames (ORFs), identified as ORF1a, ORF1b, ORF2a, ORF2b and ORF3-7 [3-6]. ORF5, ORF6 and ORF7 encode a glycosylated membrane protein GP5, a non-glycosylated membrane protein $\mathrm{M}$, and the nucleocapsid protein $\mathrm{N}[7,8]$.

Receptor-mediated endocytosis and replication are processes of PRRSV entry into host cells [9]. Here, there are six potential host cell receptors for PRRSV attachment, namely heparin sulphate, vimentin, CD151, CD163 (scavenger receptor for the haemoglobinhaptoglobin complex), sialoadhesin (CD169), and DC-SIGN (dendritic cell-specific intercellular adhesion molecule-3-grabbing non-integrin, known as CD209) [10]. GP5 is the dominant glycoprotein on the viral surface and is considered the major envelope glycoprotein. In contrast, the glycoproteins GP2, GP3, and GP4 were recognized as the minor envelope glycoproteins due to their lower presence on the viral surface [8]. Nowadays, ORF5 is being one of the most promising targets for the development of the new generation of vaccines against PRRSV. However, some of the experimentally developed PRRSV-expressing GP5 vaccines showed that the neutralizing antibodies are weak [11]. In Wang's (2009) study [12], they immunized mice and pigs with recombinant adenovirus expressing porcine GM-CSF-GP3-GP5 (rAd-GF35) and determined the responses after immunological challenges. The results described that the antibodies against PRRSV GP3/GP5 developed in animals after inoculation with rAd-GF35. Nonetheless, they did not find the secretion of IFN- $\gamma$ after challenge and they did not measure the correlation between the level of cell-mediated immunity (CMI) and viremia. IFN- $\gamma$ and TNF- $\alpha$ are important cytokines that induce the response of $\mathrm{CD}^{+} \mathrm{T}$-cells upon vaccination [13]. However, the underlying mechanism of T-cells-mediated immunity to PRRSV is not fully understood and further studies are needed.

Currently, the most efficient and functional method to prevent the PRRSV disease is vaccination. The commercially attenuated live PRRSV vaccines are a tool for valuable disease control, but have limited efficacy in protecting against infections with the genetically diverse field strains of PRRSV and carry the potential risk of becoming virulent again. Lower efficacy in preventing infectious disease has also been observed with killed PRRSV vaccines [14-17]. To date, the success of the majority of vaccines relies on their capability to target specific pathogen antigens which could induce humoral immune response in the host. On the other hand, cell-mediated immunity is less achievable with current vaccination strategies, and this leads to most chronic infections. Some developed vaccines carry several potential risks, such as the risk of co-purification of undesirable contaminants or reversal of toxoids to their toxigenic form when considering diphtheria or tetanus toxoid vaccines. Recombinant protein vaccines have the potential to avoid these potential risks [18]. B- and $\mathrm{T}$-cells have become the focus of vaccine development research in recent years. However, innate immune cells have a pivotal role in vaccination to promote the expression of longlasting adaptive immune responses. In order to get an effective vaccination, we need an immune response to immunization, and this can be provided by both the innate and adaptive immune systems. Furthermore, there are two critical points to be considered in order to produce an effective immunization, which are the induction of long-term stimulation of the humoral and cell-mediated arms of the adaptive system that can be produced by the production of effector cells and memory cells [19]. Salerno et al. (2012) [20] reported that the induction of strong and persistent memory T-cells and cell-mediated immunity (CMI) responses supported vaccination success. CMI responses were dependent on two cell types, namely $\mathrm{CD}^{+}$and $\mathrm{CD}^{+} \mathrm{T}$-cells. $\mathrm{CD}^{+} \mathrm{T}$-cells protecting the host cells from pathogen by destroying infected or tumor cells and secreting interferon- $\gamma$ (IFN- $\gamma$ ) 
and other cytokines. CD4 ${ }^{+}$T-cells play the important role in host defense supported by the two main subpopulations: Th1, which in generally trigger inflammatory responses and the differentiation of $\mathrm{CD}^{+}$cells, and Th2, which support the production of specific antibodies.

Primary porcine alveolar macrophages (PAMs) are the major target host cells of PRRSV infection and are known to express CD14, SLA II, CD163, CD169, CD203, SWC3 (CD172a), and CD16 receptors [21,22]. A previous study demonstrated that by introducing the CD163 gene alone into immortalized PAMs (iPAMs) was sufficient to restore PRRSV susceptibility, suggesting that CD163 was the sole determining factor in PAMs for PRRSV entry [23]. CD163 is a scavenger receptor expressed on monocytes/macrophages and was determined to be a well-characterized M2 marker since its expression was upregulated during macrophage differentiation of human blood monocytes stimulated by macrophage colony-stimulating factor (M-CSF) [24,25]. Moreover, CD163 reduced the expression of TNF- $\alpha$ and other pro-inflammatory factors [26]. High expression of CD163 in macrophages indicates potent anti-inflammatory potential and phagocytic ability of macrophages to clear debris and apoptotic cells [25]. Wang (2017) [27] demonstrated that the M1 type strongly inhibits replication of highly pathogenic PRRSV (HP-PRRSV), but not in M2-type PAMs. Moreover, their results showed that HP-PRRSV infection promotes the repolarization of M2-type PAMs. These findings strongly suggested that HP-PRRSV infection can modulate macrophages polarization. The presence of $\mathrm{CD}_{163^{+}}$in M2-type macrophages suppresses T-cell proliferation and pro-inflammatory cytokine secretion. On the contrary, T-cells proliferation and pro-inflammatory cytokine production was significantly increased in CD163-deficient macrophages in osteosarcoma [28]. M2 macrophage polarization was mediated by IL-4 alters secretion of IL-13 during Th2-type response. In contrast, the first line of defense against intracellular pathogens was initiated by M1 macrophages through the secretion of $I L-12$, which promoted or enhanced the Th1 type of CD4 ${ }^{+}$lymphocytes [29]. Th1 cells also provoke the production of immunoglobulin G2a (IgG2a) antibodies in B-cells to optimize the ability of viral clearance and to clear extracellular bacteria [30]. In our previous study, the production of neutralizing antibodies in vaccinated pigs was generally poor in parallel with showing an immunosuppressive serum by increasing IL-10 and Treg cells. Therefore, recombinant antigen derived from PRRSV was thought to induce immunosuppression, just as a true virus, through the induction of M2 polarization of PAMs in pigs. The aim of this study was to evaluate the effects of the two recombinant antigens, A1 (g6Ld10T) and A2 (lipo-M5Nt), with respect to their ability to mediate innate and T-cell-mediated immunity prior to humoral immunity after vaccination, as a novel vaccine candidate.

\section{Materials and Methods}

\subsection{Ethics Statement}

The lung collection and pig euthanization were approved by the Institutional Animal Care and Use Committee (IACUC) of Veterinary Medicine at National Pingtung University of Science and Technology (NPUST), Taiwan.

\subsection{Pigs and Inoculations}

This study was performed on specific pathogen free (SPF) piglets, approximately eight to eleven weeks of age and nine to twelve $\mathrm{kg}$ in weight. They were raised in a room with positive pressure in NPUST Animal Diagnostic Center.

\subsection{Constructed the Recombinant Protein Antigen}

Antigen 1 (A1) was constructed from the complete sequence of ORF5 combined with the partial sequence of ORF6 and the copies of T-cell epitopes (Supplementary material Figure S1). The recombinant antigen was expressed using the baculovirus expression system. Lipidated recombinant protein antigen 2 (A2) was constructed from the combination of the ORF5, ORF6 and ORF7 sequences and expressed using the Escherichia coli (E. coli) expression system (Supplementary material Figure S2). 


\subsection{Collecting Porcine Alveolar Macrophages (PAMs)}

Pigs were euthanized by exsanguination. The trachea was ligated to prevent total pulmonary collapse, followed by the removal of heart and lungs from the thorax. Alveolar macrophages were harvested aseptically from fresh lungs. The lungs were washed intratracheally $2-4$ times with phosphate buffered saline (PBS), and the wash fluids containing PAMs were centrifuged for $10 \mathrm{~min}$ at $800 \times \mathrm{g}$. The collected PAMs were seeded in 12-well plates and maintaining with complete RPMI-1640 medium (Corning, Manassas, VA, USA) containing $10 \%$ fetal bovine serum (FBS) (Hyclone, Logan, UT, USA) at $37^{\circ} \mathrm{C}$ in a humidified $5 \% \mathrm{CO}_{2}$ atmosphere.

\subsection{Cytokine Stimulation}

PAMs were seeded in 12-well plates and divided into five groups; control (untreated); $1 \mu \mathrm{g} / \mathrm{mL}$ LPS (Sigma-Aldrich, Steinheim, Germany) added; $20 \mathrm{ng} / \mathrm{mL}$ IL-4 (BIOTECH, INC, Alpharetta, GA, USA) added; $5 \mu \mathrm{g} / \mathrm{mL}$ of A1 added; and $5 \mu \mathrm{g} / \mathrm{mL}$ of A2 added. After $24 \mathrm{~h}$ of treatment, cells were collected to extract RNA and perform qPCR analyses.

\subsection{RNA Extraction and Quantitative Real-Time Polymerase Chain Reaction}

Total RNA was prepared using Trizol reagent (Invitrogen, Waltham, MA, USA) according to the manufacture's protocol. Total RNA $(1 \mu \mathrm{g})$ was used in the reverse transcription (RT) reaction by iScript cDNA Synthesis Kit (Bio-Rad, Hercules, CA, USA). The quantitative real time PCR was performed using KAPA SYBR ${ }^{\circledR}$ FAST qPCR Master Mix (2X) Kit (KAPA Biosystem, Wilmington, DE, USA) according to the manufacturer's protocol. Quantitative PCR reactions were performed using a QIAGEN Rotor Gene Q Real-Time PCR. $\beta$-actin was used as the endogenous reference gene since it has the highest stability across pig tissues compared to the other reference genes [31]. The primer sequences $\left(5^{\prime}-3^{\prime}\right.$; forward, reverse) were showed in Table 1 . The amplification steps were set for $3 \mathrm{~min}$ at $95^{\circ} \mathrm{C}$, followed by 40 cycles of denaturation at $95^{\circ} \mathrm{C}$ for $3 \mathrm{~s}$, and annealing at $60^{\circ} \mathrm{C}$ for $20 \mathrm{~s}$. The data were calculated using the standardized mRNA level comparative methods $2^{-\Delta \Delta C t}$. The $2^{-\Delta \Delta C t}$ method is a convenient way to analyze the relative changes in gene expression with a high efficiency qPCR assay [32].

Table 1. Primer sequences.

\begin{tabular}{|c|c|}
\hline Gene Name & Primer Sequences $\left(5^{\prime}-3^{\prime}\right)$ \\
\hline \multirow{2}{*}{ Porcine $I L-6$} & GCTGCTTCTGGTGATGGCTACTGCC \\
\hline & TGAAACTCCACAAGACCGGTGGTGA \\
\hline \multirow{2}{*}{ Porcine $T N F-\alpha$} & ATGAGCACTGAGAGCATGATCCG \\
\hline & CCTCGAAGTGCAGTAGGCAGA \\
\hline \multirow{2}{*}{ Porcine Arg-1 } & AGCCCGTGTCAACATGACTTCC \\
\hline & TTGTGTTGGCATCTTTACTGA \\
\hline \multirow{2}{*}{ Porcine $I L-12$} & CTCCCACACCGAAGCTTGAA \\
\hline & TTCTTCACCATGGGGGCT \\
\hline \multirow{2}{*}{ Porcine $\beta$-actin } & ACAGACAGCCGTGTGTTCC \\
\hline & ACCTTCACCATCGTGTCTCA \\
\hline
\end{tabular}

\subsection{Next Generation Sequencing (NGS) Analysis}

The cDNA libraries were collected from pooling of six independent samples in each group. Then, cDNA libraries were assessed on the Agilent Bioanalyzer 2100 system and a Real-Time PCR system. Housekeeping gene ( $\beta$-actin) was served as an internal control to verify the cDNA quality and quantity in PCR. NGS was performed externally at the Genomics on an Illumina Novaseq 6000 with 150 bp paired-end reads (Genomics, BioSci \& Tech Company, New Taipei City, Taiwan). Raw-sequencing reads were filtered using the 
program Trimmomatic (version 0.36) [33]. Read alignments were assembled using Bowtie2 (version 2.3.5) [34]. The raw gene counts were extracted with RSEM (version 1.3.3) [35]. The R package EdgeR v3.16.5 tool was used for differential gene expression analysis between two sample groups. In addition, the $\log _{2}$ Fold Change $\left(\log _{2}\right.$ FC) was calculated using the $\log _{2}$ (sample count A/sample count B). Significant differences between two sets of samples were identified by t-test with $p<0.05$. A gene ontology (GO) enrichment analysis was conducted on the differential genes obtained through screening, and when $p<0.05$, the GO terminology is regarded as significantly enriched [36]. The Kyoto Encyclopedia of Genes and Genomes (KEGG, https:/ / www.genome.jp/kegg/kegg2.html (accessed on 26 January 2021). was used for gene enrichment of differentially expressed genes [37]. The datasets presented in this study can be found in online repositories (NCBI Bioproject PRJNA665327:https:/ / dataview.ncbi.nlm.nih.gov / object/PRJNA726625) (accessed on 1 May 2021).

\subsection{Integration of the Protein-Protein Interaction (PPI) Network}

The potential differential expression gene (DEG) interactions at the protein level were explored by the Search Tool for the Retrieval of Interacting Genes (STRING; string-db.org). The PPI networks of DEGs by STRING were derived from validated experiments. $p<0.05$ was considered to indicate a statistically significant difference.

\subsection{Isolation of Porcine Peripheral Blood Mononuclear Cells (PBMC)}

Peripheral blood mononuclear cells (PBMCs) were isolated by using Ficoll-Paque (GE Healthcare BioScience, Uppsala, Sweden) density-gradient centrifugation at $400 \times g$ for $30 \mathrm{~min}$ according to the manufacturer's instructions. PBMCs were washed three times in RPMI 1640 (Corning, Manassas, VA, USA), and resuspended in advanced RPMI 1640 medium containing 10\% fetal bovine serum (FBS) (Hyclone, Lo-gan, UT, USA) for further experiments.

\subsection{Fluorescence Activated Cell Sorting (FACS) for T-Cell Subsets}

For T-cells subset, PBMCs were sorted by FACS into subpopulations for co-culture experiments. Briefly, $1 \times 10^{6}$ cells $/ \mathrm{mL}$ were stained with $0.05 \mu \mathrm{g}$ anti-pig FITC-CD4 ${ }^{+}$ antibody (Ab24989, Abcam, Cambridge, UK) and $10 \mu \mathrm{g}$ anti-pig CD25 ${ }^{+}$primary antibody (MCA1736GA, Bio-Rad) on ice in dark for $30 \mathrm{~min}$, followed by staining with $5 \mu \mathrm{g}$ antimouse R-Phycoerythrin-conjugated IgG1 secondary antibody (STAR132PE, Bio-Rad) on ice in dark for $30 \mathrm{~min}$. Hereafter, the stained cells were washed twice with cold PBS before acquisition on BD FACS Aria II cells sorter (BD Biosciences, San Jose, CA, USA). Two subpopulations of $\mathrm{T}$ cells were sorted based on the expression of $\mathrm{CD}^{+} \mathrm{CD} 25^{-}$(Th1) and $\mathrm{CD}^{+} \mathrm{CD} 25^{+}$(Treg).

\subsection{Flow Cytometry Analysis}

PAMs $\left(1 \times 10^{6}\right.$ cells $\left./ \mathrm{mL}\right)$ were collected and washed once with cold PBS containing 0.5\% BSA (Sigma-Aldrich, Steinheim, Germany). Cells were incubated with fluorescenceconjugated antibodies in $1 \mu \mathrm{g}$ FITC-SLA II ${ }^{+}$(Bio-Rad), $5 \mu \mathrm{g}$ FITC-CD14 ${ }^{+}$(Invitrogen), $0.1 \mu \mathrm{g}$ APC-CD80 ${ }^{+}$(Invitrogen), and 1:10 dilution of PE-CD163 ${ }^{+}$(Invitrogen), on ice in dark for $30 \mathrm{~min}$. The cells were then washed by centrifugation at $300 \times g$ for 5 min and resuspended in $500 \mu \mathrm{L}$ to $1 \mathrm{~mL}$ of cold PBS. The expression of surface protein on cells were measured by using the flow cytometry (BD Biosciences, San Jose, CA, USA), and the analysis was performed using BD FACSDiva Software (BD Biosciences) and FlowJo Software (Tree Star, Inc., Ashland, OR, USA).

\subsection{Th1 Cytokines Assay}

In an indirect transwell co-culture system, $2 \times 10^{6}$ PAMs were seeded at the bottom of the transwell system overnight. Then after, the cells were stimulated by antigens A1 or $\mathrm{A} 2$ and $2 \times 10^{5} \mathrm{~T}$-cells subset $\left(\mathrm{CD} 4^{+} \mathrm{CD} 25^{-}\right.$or $\left.\mathrm{CD} 4^{+} \mathrm{CD} 25^{+}\right)$were seeded into the upper 
chamber of the transwell insert, simultaneously. The co-culture dish was followed by incubation in standard conditions $\left(5 \% \mathrm{CO}_{2} ; 37^{\circ} \mathrm{C}\right)$ for $48 \mathrm{~h}$. Then, conditioned medium was collected for Th1 cytokines assay. Briefly, cytokine concentrations were determined from a standard curve created by a reference preparation of IL-10, IFN- $\gamma$ (Thermo Fisher Scientific, Vienna, Austria) and IL-12 (R\&D System, Abingdon, United Kingdom) from commercial ELISA kit according to the protocols provided by the manufacturers. The optical density A450 nm of each well was measured by EZ Read 400 Microplate Reader (Biochrom, Cambridge, UK).

\subsection{Statistical Analysis}

Data were presented as mean \pm SEM when indicated. Statistical analysis was conducted by $t$-test with a $95 \%$ confidence limit, and one-way ANOVA followed by Tukey's test for multi comparisons based on a Shapiro-Wilk test for normality. The data analysis was performed using Prism 8.0 (GraphPad Software Inc., San Diego, CA, USA). Differences were considered significant at $p<0.05$.

\section{Results}

\subsection{A1 Directs Macrophages Polarization toward M1 Macrophages and Downregulation of} CD163 Expression

A homogeneous and stable subset of cells compatible with PAMs due to their size and granularity were identified in all control and PRRSV-infected pigs. However, this subset decreased proportionally in infected groups compared to the control. We presented the gating strategy to obtain the living cells in terms of cell size and granularity based on forward light scatter/side light scatter (FSC-A/SSC-A) and excluded the aggregated cells by FSC-W/FSC-H as well as SSC-W/SSC-H (Figure 1a). Since PAMs represent the PRRSV target cells in pigs, the first objective of our study was to determine the specific markers associated with these cells. Among them, CD14 was first investigated as a marker of the myelomonocytic phenotype. A representative histogram is shown in Figure 1b-d. Furthermore, PAMs are known to express both SLA II and CD163 receptors [38]. In agreement with the previous literature, we confirmed that $91.3 \%, 97.5 \%$, and $95.2 \%$ PAMs isolated from healthy pigs expressing CD14, SLA II, CD163 positive, respectively. On the contrary, only a small percentage of cells $(23.8 \%$ and $23.1 \%)$ expressing $\mathrm{CD} 14^{+}$and $\mathrm{CD} 163^{+}$ were found in PAMs isolated from PRRSV-infected pigs. This result complements an article which demonstrated that the proportion of $\mathrm{CD}_{163^{+}}$cells was decreased after eight days post-infection of PRRSV [39]. Meanwhile, our result also showed a significant decrease in the percentage of cells expressing $\mathrm{CD} 14^{+}$, SLA II ${ }^{+}$, and $\mathrm{CD}_{163}{ }^{+}$between PRRSV-infected and healthy pigs (Figure 1e). Nevertheless, the mean fluorescence intensity (MFI) of CD14 ${ }^{+}$ and $\mathrm{CD} 163^{+}$was significantly higher in PAMs isolated from PRRSV-infected pigs. The increase in $\mathrm{CD}_{1}{ }^{+}$indicates a strong infiltration of monocytes in the lungs, which is in agreement with the statement of Van., et al. (2004) [40], who showed that CD14 was significant increase in the lungs of pigs after PRRSV infection. A significant increase in MFI of $\mathrm{CD}_{163}{ }^{+}$during late gestation and PRRSV type 2 infection in pregnant gilts was also demonstrated in the previous study by Novakovic, et al. (2016) [41]. Moreover, the significant increase in MFI of $\mathrm{CD} 163^{+}$in PRRSV-infected pigs probably was due to the polarization of the M2 phenotype after infection, and indicates that CD163 plays an important role in receptor for viral infection (Figure 1f). 
(a)
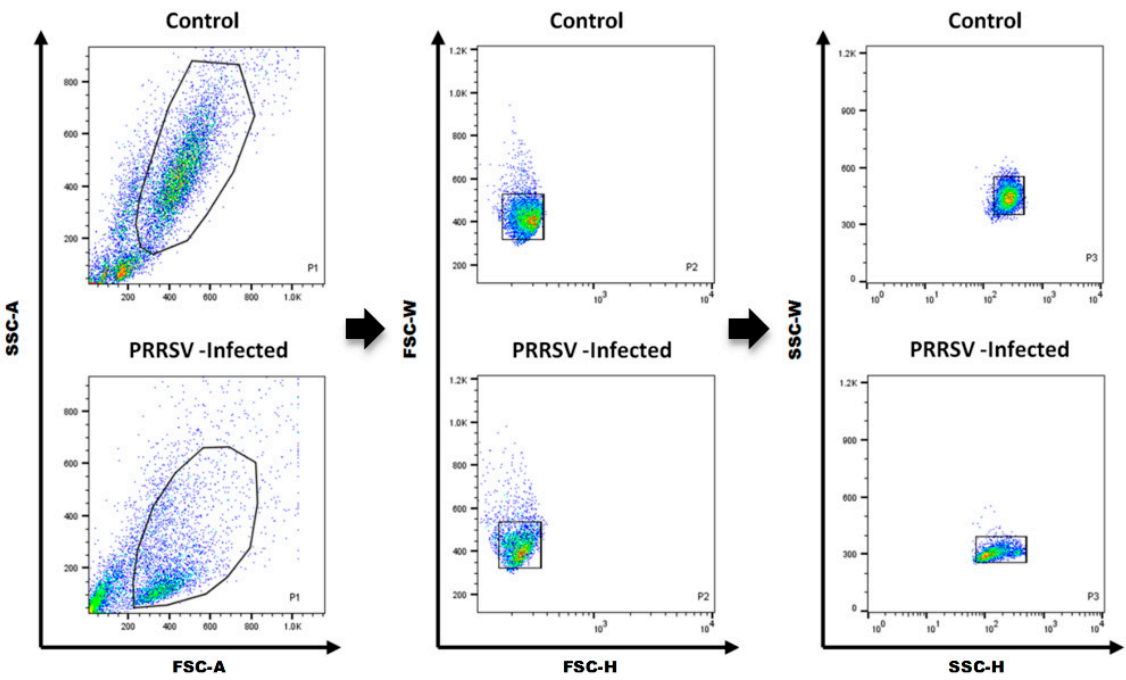

(b)
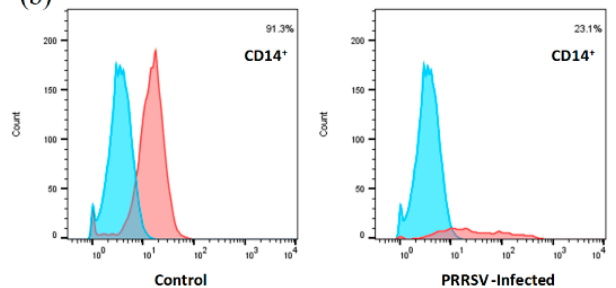

(d)
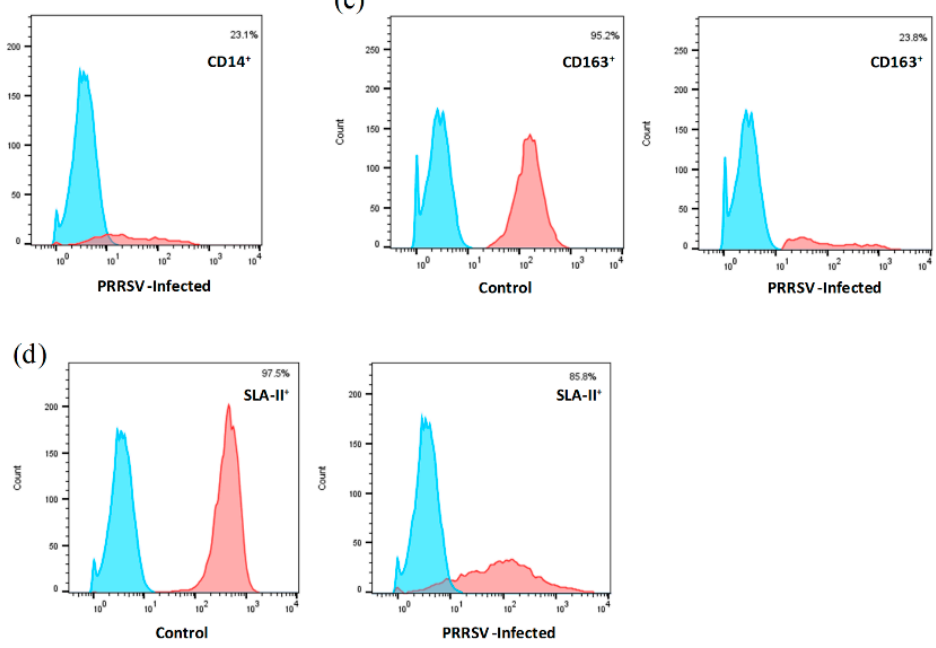

(e)

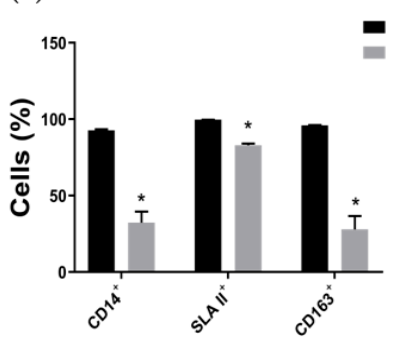

(f)

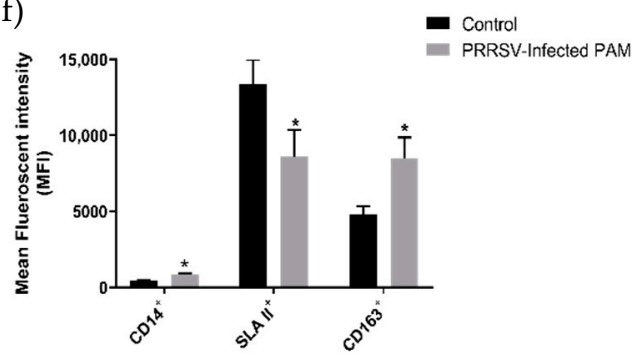

Figure 1. Surface marker expression on alveolar macrophages from animals infected with PRRSV. (a) Gating strategy of healthy PAMs and PRRSV-Infected PAMS. Dot plots (FSC-Area vs. SSC-Area) from a representative pig of the control and PRRSV-infected group. We excluded more dead cells in the lower levels of FSC/SSC. The circles indicate living potential of PAMs according to light scatter properties (size and granularity). The combination of width and height of FSC and SSC, respectively, indicate the singlets of cells. (b-d) Representative flow cytometry histogram of PRRSV-infected PAMs. Samples were calculated from three pigs (duplicate each pig). Red color histogram represents signal for each specific antibody, and blue color histogram represents unstained. Cells percentage $(\mathbf{e}, \mathbf{f})$ mean fluorescence intensity (MFI) of CD14 ${ }^{+}, \mathrm{SLA} \mathrm{II}^{+}$ and $\mathrm{CD}_{163}{ }^{+}$were detected with a specific monoclonal antibody, followed by a FITC-conjugated anti-mouse antibody and analysis by flow cytometry. The level of expression of non-infected animals is included as a control. Statistical differences were established by mean $\pm \operatorname{SEM}(* p<0.05)$. 
To further validate the effect of antigens on macrophages polarization, we challenged PAMs with recombinant PRRSV-2 antigens (A1 and A2). The results showed that PAMs challenged with A1 enhanced the upregulation of pro-inflammatory genes (TNF- $\alpha, I L-6$ and $I L-12)$, suggesting that A1 promotes M1 macrophages polarization, but not in PAMs challenged with A2. In contrast, A2-challenged PAMs up-regulate the expression of Arg-1, one of the anti-inflammatory gene representatives for M2 macrophages (Figure 2a). These results suggest that A1 may be a candidate for inhibiting PRRSV infection by regulating macrophages polarization. There were no significant differences on SLA II ${ }^{+}$and $\mathrm{CD} 80^{+}$ surface protein marker between A1 and A2 induction. However, the number of cellsexpressing $\mathrm{CD}_{163}{ }^{+}$were significantly decreased after they were treated with A1 (Figure $2 \mathrm{~b}$ ).
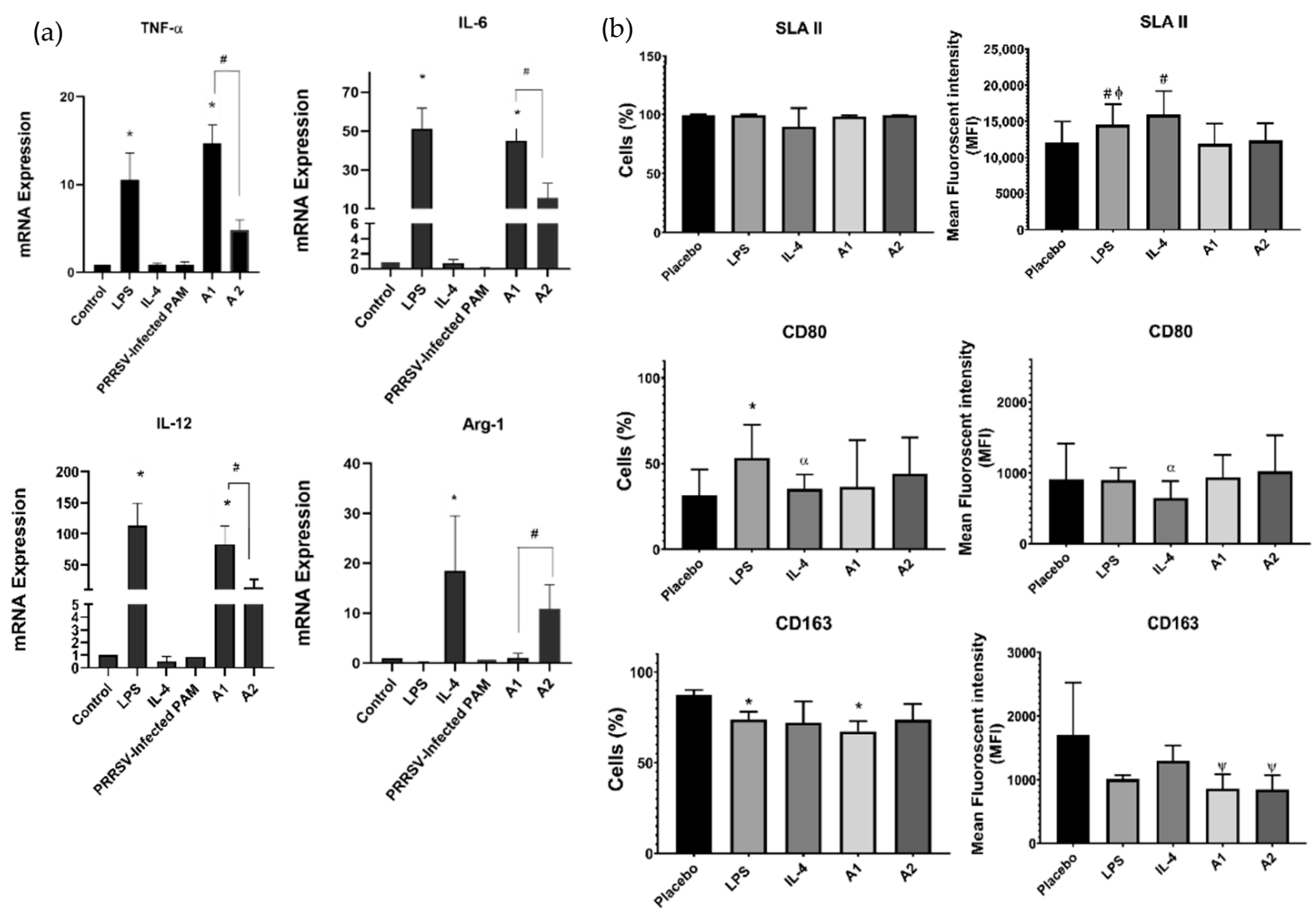

Figure 2. A1 drives M1 macrophages polarization and the expression of CD163 on PAMs was significantly decreased. (a) mRNA expression profile of M1 and M2 macrophages of PAMs-challenged by PRRSV-2 antigens measured by quantitative PCR (qPCR). A1 promote up-regulation the mRNA level of pro-inflammatory genes and down-regulate the anti-inflammatory genes. (b) The expressions of surface protein SLA II ${ }^{+}, \mathrm{CD}^{2} 0^{+}$and $\mathrm{CD}_{163}{ }^{+}$in macrophages by flow cytometry. A1 decreased the cells percentage of $\mathrm{CD}_{163^{+}}$on PAMs. PAMs were treated by LPS, IL-4, A1, or A2 for $24 \mathrm{~h}$. Untreated PAMs were used as control. ${ }^{*} p<0.05$ compared to control group; $\alpha p<0.05$ compared to LPS group; $\psi p<0.05$ compared to IL-4 group; \# $p<0.05$ compared to A1 group; $\phi p<0.05$ compared to A2 group. The data were analyzed by mean \pm SEM, calculated from 3 pigs (duplicate each pig).

\subsection{A1 Stimulate Endogenous Pro-Inflammatory Gene for T-Cell Receptor (TCR) Signaling Pathway}

To verify additional pro-inflammatory genes involved in the regulation of macrophages polarization by these recombinant antigens, we next performed transcriptome analysis of PAMs challenged with A1 versus A2. Our results showed that some of the proinflammatory genes, such as $N f-k B, N N T, T N F-\alpha$, and JARID2, were included in the top 50 upregulated genes in PAMs challenged by A1 (Figure 3a). In contrast, some of antiinflammatory genes, such as Arg-1, SLC7A6, MAP4, and GATAD2A, were included in total top 50 downregulated genes (Figure $3 b$ ). Some of the differential expression genes also showed the significant changes in A1 compared to control (shown in the highlighted 
bars). We interestingly found that several special genes have different variants in the heatmap. These genes with the variants were represented by the code number on the Y-axis of the heatmap (Supplementary Material Figure S3a). Except for this, the majority of anti-inflammatory genes among the variants were downregulated in A1 compared to $\mathrm{A} 2$, such as CD274 and UBAP2L. In contrast, the majority of TLR 8 variants, one of inducer of IFN- $\gamma$, were up-regulated in A1 compared to that in A2. In order to verify the quality and quantity of cDNA libraries in the PCR conditions, we used the $\beta$-actin as an internal control. Our results showed that the melting curve of $\beta$-actin reflects the specific amplicon in RT-PCR (Supplementary Material Figure S3b). In addition, the cycle threshold $(\mathrm{Ct})$ values of $\beta$-actin in all samples among the groups were in consistency, by a range of 19-24, showing no significant differences statistically (Supplementary Material Figure S3c). Our $\beta$-actin gene expression level was also elucidated from the NGS data, which also manifested no significant differences among the groups by $\log _{2}$ FC value (Supplementary Material Figure S3d). According to these aforementioned results, the quality and quantity of cDNA libraries were identical among the groups. There were some overlapping genes among the A1 and A2 (Figure 3c). Furthermore, the data showed that there were 8 overlapping pathways enriched in up- and down-regulated genes. Nevertheless, T-cell receptors (TCRs) signaling pathway was enriched only in up-regulated genes, which were promoted by A1. This finding strongly suggests that endogenous genes expressed in A1-challenged PAMs promote the activation of TCR signaling pathway and regulate the immune system process (Figure 3d,e).

(a)

$$
\text { Up-regulated Genes }
$$

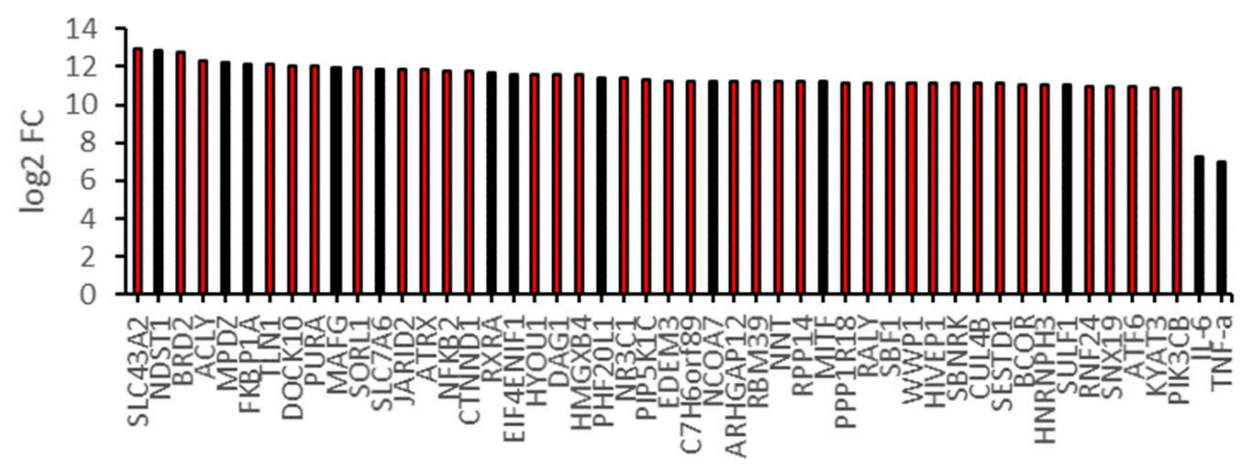

(b)

Down-regulated Genes

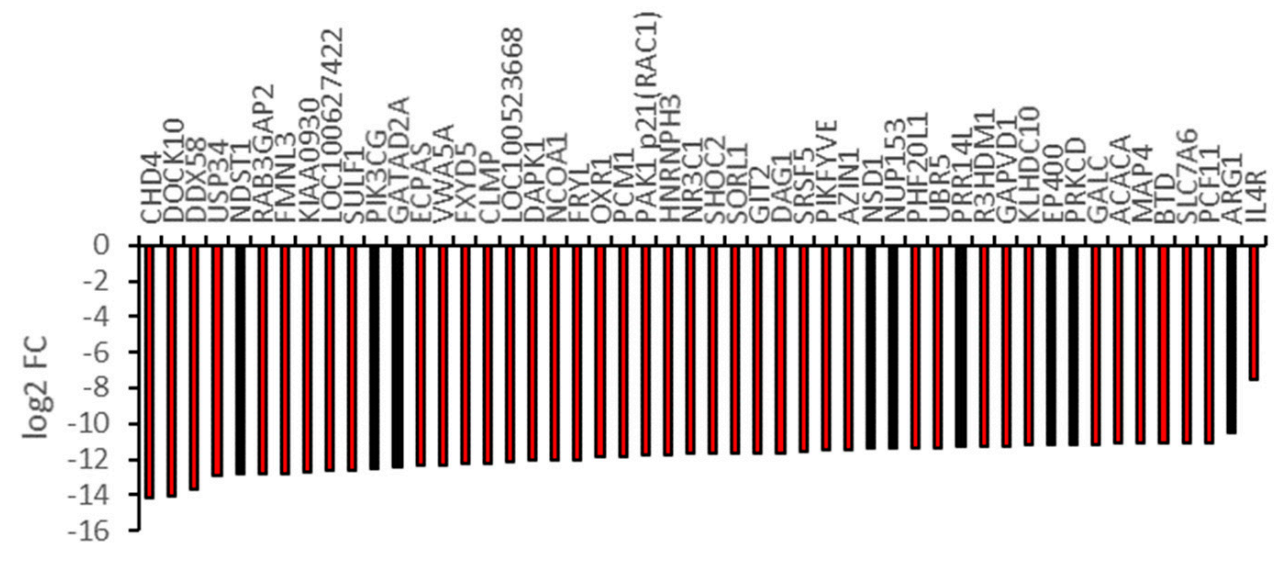

Figure 3. Cont. 
(c)

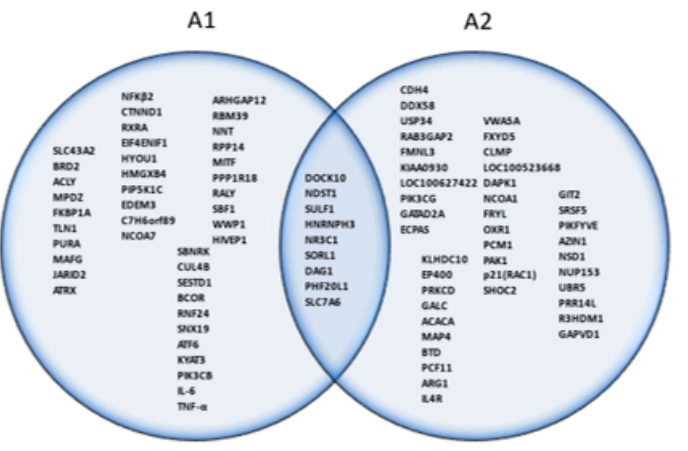

(d) Cysteine and methationine metabolism

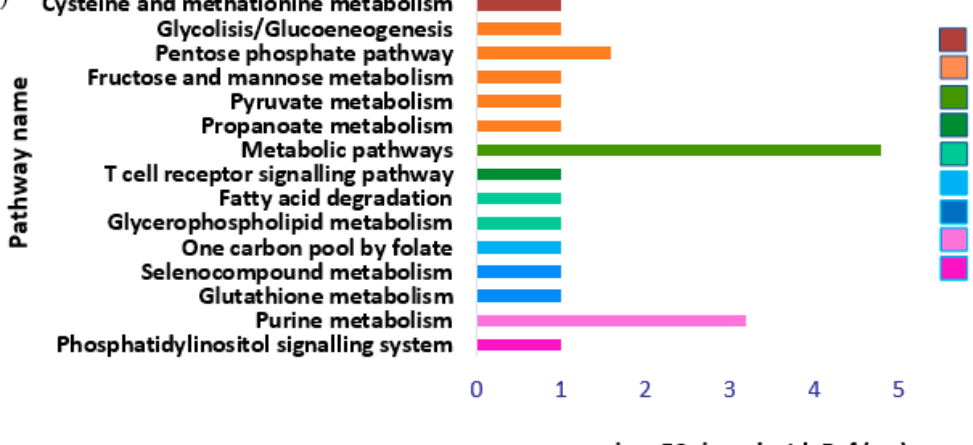

amino acid metabolis carbohydrate metabolism global and overview maps immune system lipid metabo lism metabo lism of cofactor and vitamins metabo lic of other amino acids nucleotide metabolism signal transduction

$\log _{2}$ EC shared with Ref (ssc)

(e)

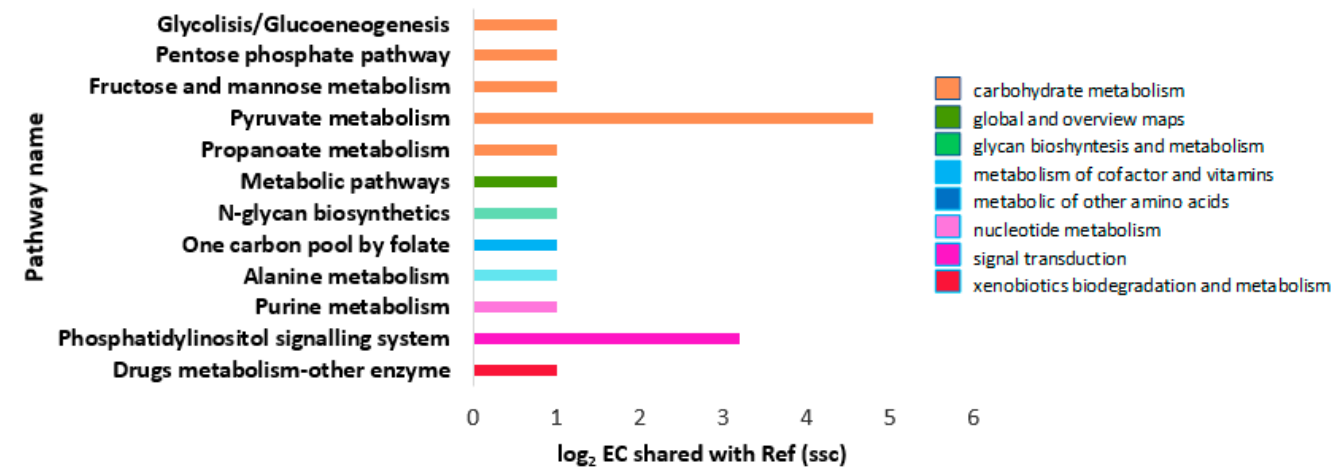

Figure 3. Transcriptome Profiling by Next Generation Sequencing in PAMs challenged with Antigens. Top 50 (a) upregulated and (b) down-regulated differentially expressed genes in PAMs challenged by A1 compared to A2. The highlighted bars indicate the same pattern of the expressed genes while A1 was compared to the control. (c) Venn diagram based on the overlapping differentially expressed genes in PAMs challenged by A1 compared to A2. (d) Up-regulated and (e) downregulated pathways stimulated by A1. The T-cell receptor signaling pathways were up-regulated on A1 challenged.

\subsection{A1 Potentially Regulate Immune Response by Promoting Rap1 Signaling Pathway and Protein-Protein Interaction (PPI) Network}

Furthermore, we investigated the correlating genes involved in the immune response process in their respective signaling pathways using the Kyoto Encyclopedia of Genes and Genomes (KEGG) enrichment analyses mapping tool. Surprisingly, we found that the Rap1 pathway, the key regulator of T-cells activation, was highly enriched in PAMs induced by A1 (Figure 4a). Consistent with our previous finding, the Rap1 pathway could be stimulated by TCR activation, leading to proliferation, survival, and gene activation (Figure $4 b$ ). Similarly, we found that the C-type lectin receptors (CLRs) signaling pathway were also enriched. CLRs promote various signaling pathways that lead to the expression of specific cytokines that determine T-cell differentiation status [42]. To investigate the 
potential protein-level interactions of differentially expressed genes (DEG) in regulating the immune response, we generated an analysis of predicted protein-protein interactions (PPI) of differentially expressed genes using Search Tool for Retrieval of Interacting Genes (STRING) analysis. The results showed that some of the predicted proteins secreted by PAMs challenged by A1 were correlated with inflammatory and immune responses, such as caspase1, IL-18, PIK3CB, and IKKB (Figure 4c).

(a)

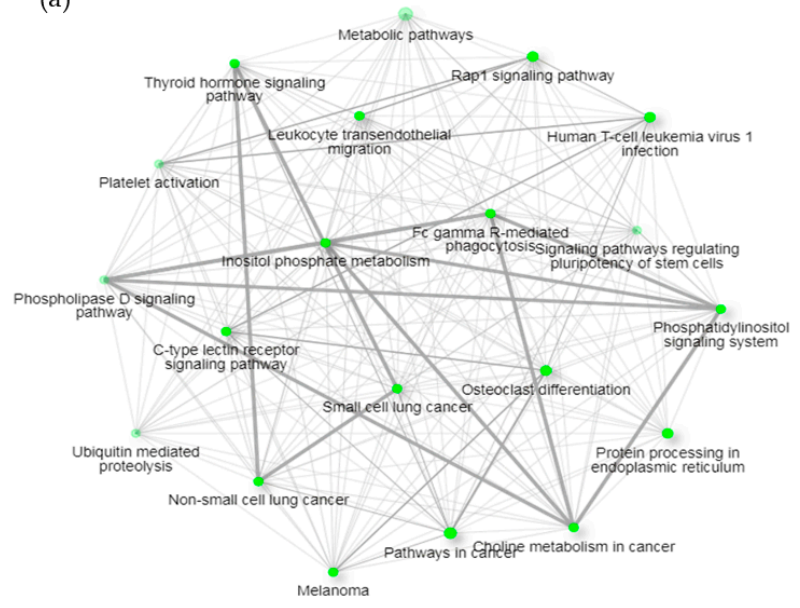

(c)

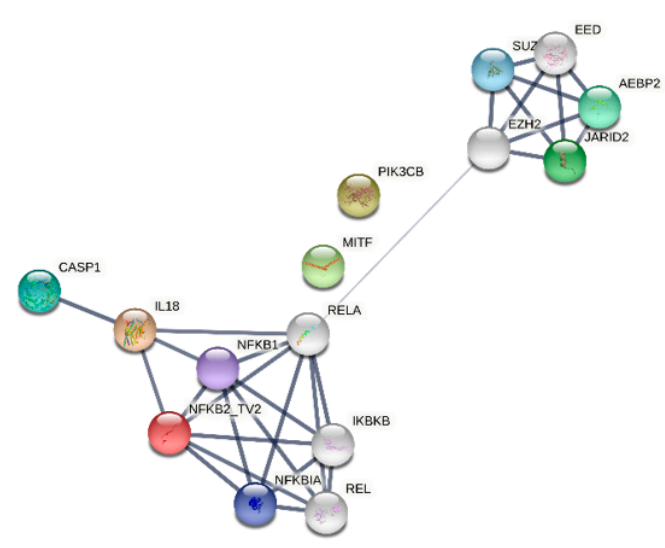

(b)

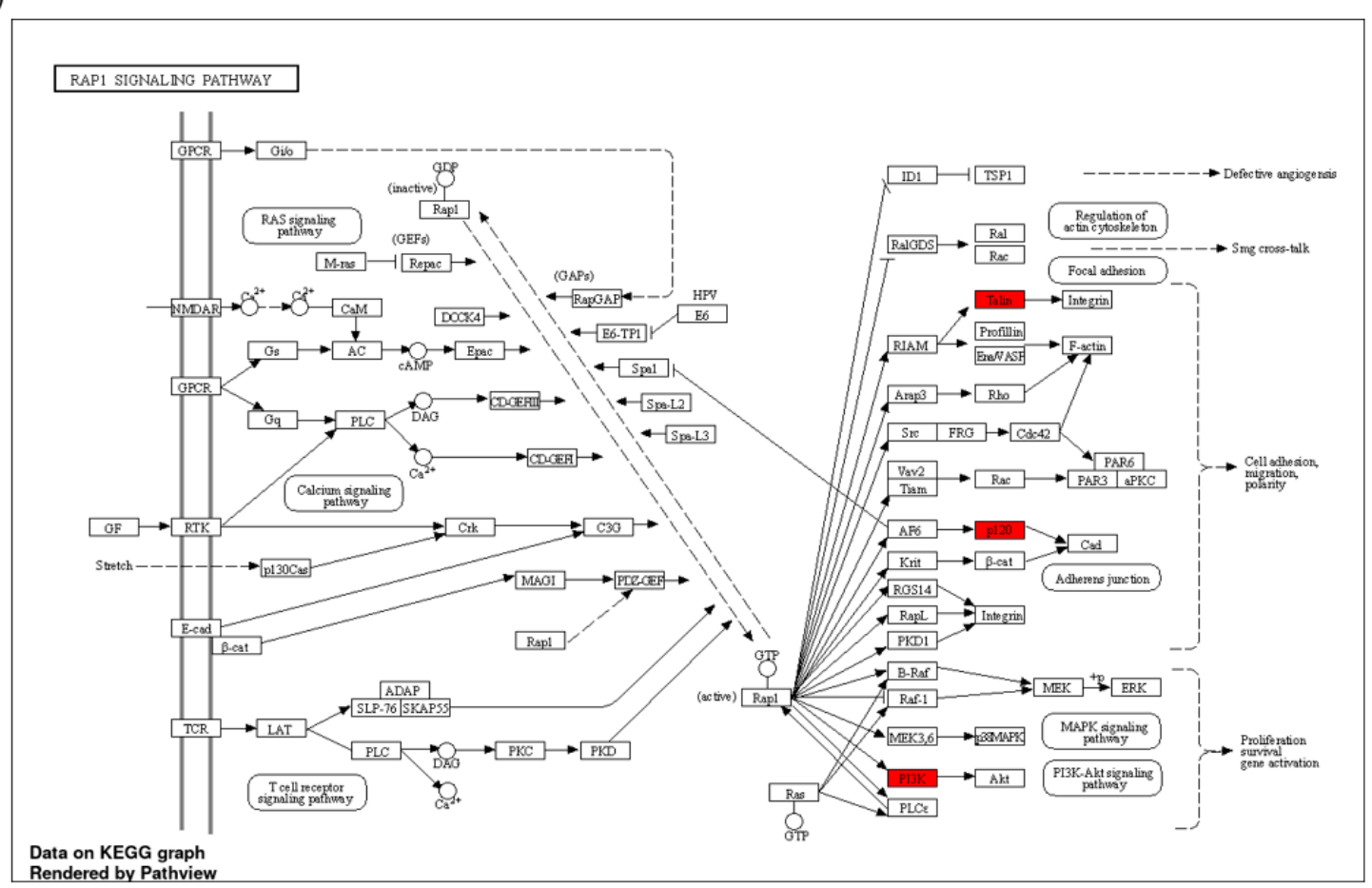

Figure 4. Network displaying the predicted interaction of signaling pathways and cytokine-related genes involved in immune response process. (a) Relationship between enriched pathways enhanced by up-regulated genes by A1 induction. Nodes represent each pathway; two nodes are connected if they share $20 \%$ or more genes. Darker nodes are more significantly enriched gene sets. Bigger nodes indicate larger gene sets. Thicker edges represent more overlapped genes. (b) Rap1 signaling pathways mediate TCR signaling pathway activation, thus promote proliferation, survival, and gene activation. Three out of 50 up-regulated genes are represented by the red box. (c) Protein-protein interactions involved in the activity of the immune response. Nodes with different colors represent different enriched proteins. 
On the other hand, downregulation of anti-inflammatory genes could act to suppress estrogen signaling, as in the KEGG mapping tool (Figure 5a,b). Additionally, these genes likely stimulate the downregulation of three negative regulator proteins of T-cell activation, namely ISG15, USP18, and DAPK1, as shown in Figure 5c.

(a)

Inositol phosphate metabolism

Metabolic pathways

Estrogen signaling pathway (c)

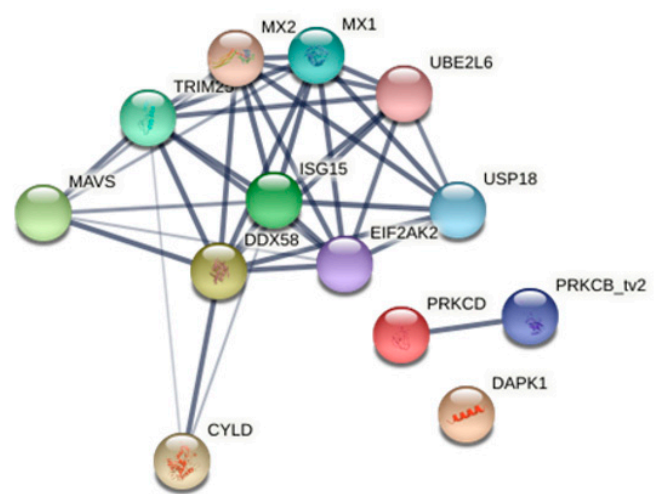

(b)

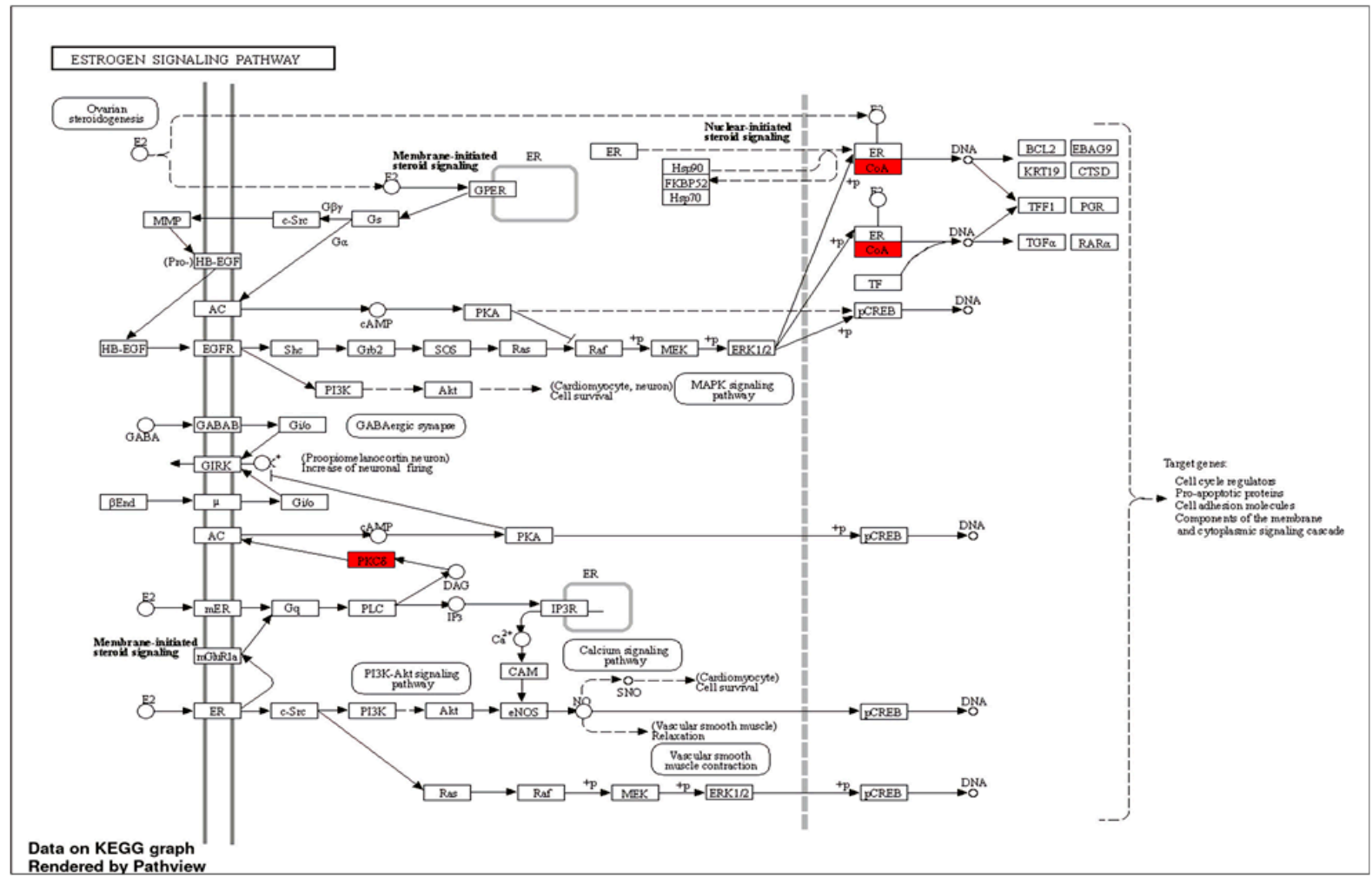

Figure 5. Network displaying the predicted interaction of signaling pathways and cytokine-related genes affected by suppression of anti-inflammatory genes. (a) Relationship between enriched pathways enhanced by down-regulated genes in A1-challenged. Nodes represent each pathway; two nodes are connected if they share $20 \%$ or more genes. Darker nodes are more significantly enriched gene sets. Bigger nodes indicate larger gene sets. Thicker edges represent more overlapped genes. (b) Estrogen signaling pathways and (c) protein-protein interactions showing predicted interactions between proteins encoded by down-regulated differentially expressed genes. Nodes with different colors represent different enriched proteins. Filled nodes indicate that a 3D structure is predicted. Edges represent protein-protein association or contribute a shared function. 


\subsection{PAMs Induced by A1 Activate Th1-Cells by Boosting Th1 Cytokine Secretion and TNF- $\alpha$ Expression}

It is generally believed that T helper (Th1) and regulatory T-cells (Treg) play an important role in dampening immune responses to antigens. To determine whether PAMs challenged by A1 are able to induce significant modulations in the mRNA level of transcription factors and cytokines related to the differential polarization of the T-cells immune response (Th1 and Treg), we observed the cytokine secretion profile of IL-10, $I L-12$, and IFN- $\gamma$ using ELISA. The results showed that there was no significant difference in the secretion of IL-10 (Figure 6a). Remarkably, A1 induced the secretion of IFN- $\gamma$ from PAMs co-cultured with Th1 cells (Figure 6b), representing a Th1 cells activation. Recently, Tregs have been shown to inhibit the proliferation of several immune cells, including B-cells, natural killer (NK) cells, natural killer T (NKT) cells, $\mathrm{CD}^{+}$, and $\mathrm{CD} 8^{+} \mathrm{T}$-cells, as well as monocytes and dendritic cells (DCs) [43]. Additionally, IL-12 was released from both Th1/Treg cells triggered by A1 (Figure 6c). Related to these results, real-time quantitative RT-PCR analysis showed that A1-challenged PAMs cocultured with Th1 up-regulated the expression of IL-6 (Figure 6d). Interestingly, cell-cell interaction of A1-induced PAMs with T cells increased TNF- $\alpha$ expression up to 80-fold (Figure 6e), compared with A1-induced PAMs alone in monoculture system, as shown in our previous result (Figure 2a). However, there were no significant differences in Arg-1 expression (Figure 6f). We emphasize that the Th1-type immune response stimulated by A1 is purely derived from A1 protein itself, since the baculovirus expression system has advantages of free endotoxin in recombinant protein production compared to that from the E. coli expression system we used for A2 production. Cox (2009) [44] have shown that the baculovirus expression vector system produces large amounts of proteins that have similar biological activities to the original proteins than proteins expressed in bacterial systems. In addition, the use of insect cells can help to eliminate endotoxin contamination, leads to endotoxin-free recombinant antigen, and stimulates cytokine secretions. In contrast, the E. coli expression system has several disadvantages, including the LPS endotoxin [45]. LPS contains lipid A, a non-repeating "core" of oligosaccharide that has the endotoxic properties and is recognized by its Toll Like Receptor 4 (TLR4). It was known that TLR4 is expressed on the cell surface of macrophages and the activation of TLR4 mediates the inflammatory response in lung macrophages [46].

(a)

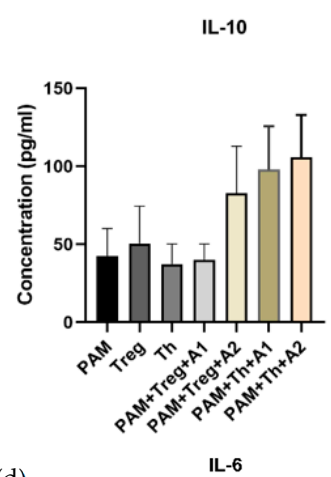

(d)

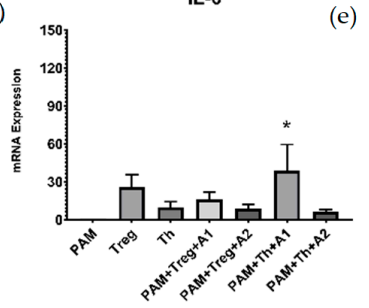

(b)

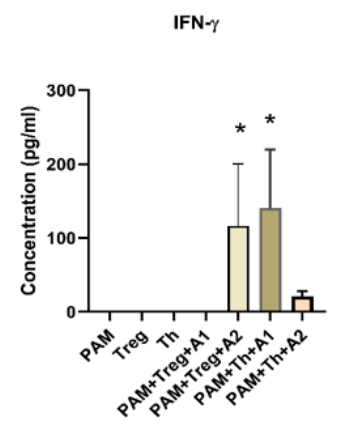

)

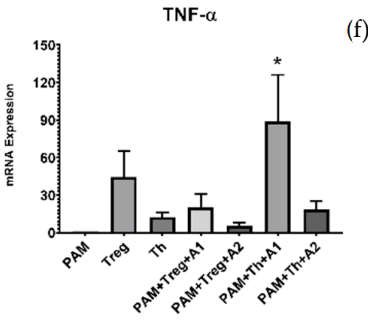

(c)

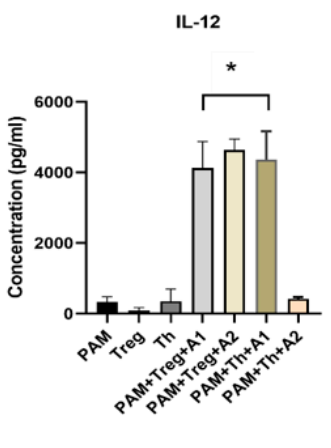

)

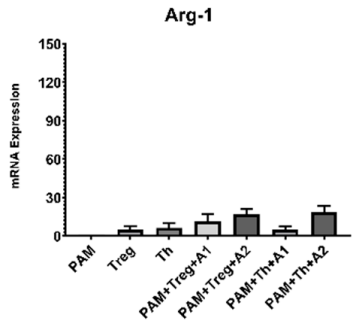

Figure 6. PAMs induced by A1 Activate Th1 cells. The conditioned medium was collected from PAMs on $48 \mathrm{~h}$ post-challenge and analyzed by ELISA to determine cytokine levels: (a) IL-10, (b) IFN- $\gamma$, (c) IL12. Each bar represents the number of cytokines secreted by individual samples. Pro-inflammatory 
gene expression determined by real-time PCR. The genes profile of (d) IL-6, (e) TNF- $\alpha$ were upregulated by challenge with A1, but no any significant at (f) Arg-1. Isolated PAMs were challenged with antigens followed by co-cultured with $\mathrm{CD} 4{ }^{+} \mathrm{CD} 25^{+}$Tregs or $\mathrm{CD} 4{ }^{+} \mathrm{CD} 25^{-}$Th1 cells for $48 \mathrm{~h}$. Protein concentrations were measured by ELISA and determined by mean $\pm \mathrm{SEM}$, calculated from 3 pigs (duplicate each pig), ${ }^{*} p<0.05$ compared to PAMs group.

\section{Discussion}

PRRSV infection was indicated by pregnancy loss and poor reproductive performance in pregnant sows, while in young pigs and in piglets it showed in symptoms such as respiratory distress and high excess mortality [47]. In PRRSV, the major envelope glycoprotein (GP5) encoded by ORF5 forms a heterodimer membrane protein with non-glycosylated $M$ protein encoded by ORF6. ORF7 encodes the nucleocapsid (N) protein and is known to be highly immunogenic in infected animals [48]. Here, we observed the two types of recombinant proteins mainly derived from antigenic epitopes of PRRSV-2 in stimulating innate and T-cell-mediated immunity as a novel vaccine candidate against PRRSV. A1 was designed from the complete sequence of ORF5 in combination with a partial sequence of ORF6 and provided with copies of T-cell epitopes so that it was delivered by the baculovirus expression system. Sewel et al., 2020, [49] showed that T-cells play an important role in protecting against many viral infections through processes known as cellular immunity. A2 was constructed as a lipidated recombinant protein containing ORF5, ORF6 and ORF7 generated using the E. coli expression system.

PRRSV specifically infects certain subsets of differentiated macrophages in the lung and replicates in monocytic lineage cells, particularly porcine alveolar macrophages (PAMs) [27]. Macrophages play an important role in immune effectors and antigen presenting cells [50]. According to their functions and expression markers, macrophages were classified into classically activated macrophages (M1/kill macrophages) and alternatively activated macrophages (M2/repair macrophages) [51-53]. M1 macrophages were characterized by high expression levels of the major histocompatibility complex class II (MHC II), the $\mathrm{CD}^{+} 8^{+}$marker, and the co-stimulatory molecules $\mathrm{CD}^{+} 0^{+}$and $\mathrm{CD}^{+} 6^{+}$. In addition, upregulation of the intracellular protein Suppressor of Cytokine Signaling 3 (SOCS3) and activation of inducible nitric oxide synthase (NOS2 or iNOS) have been demonstrated in M1 macrophages. In contrast, activation of M2 macrophages results in the secretion of high amounts of IL-10 and low amounts of $I L-12$. To promote their growth, they have also been shown to express high amounts of E- and C-type scavenger mannose and galactose receptors [54]. The expression of some surface markers such as mannitol receptor, CD206, CD163, CD209, FIZZ1, and Ym1/2 were also used to identify M2 macrophages [55].

In terms of mean fluorescence intensity (MFI), the expression of CD163 was significantly up-regulated on PAMs infected with PRRSV, but not with A1 (Figures 1f and 2b). However, the total percentage of $\mathrm{CD}_{163}{ }^{+}$cells was significantly decreased after A1 challenge (Figure 2b). A study proved that CD163 is critical for PRRSV replication and plays an important role in mediating viral internalization and degradation. Overexpression of CD163 contributes to the susceptibility of non-permissive cell lines to PRRSV infection. By binding to the three structural proteins GP2, GP4 and GP5, CD163 mediates entry and attachment of the virus to susceptible host cells [56].

Since macrophages polarization plays an important role in PRRSV infection, we then characterized M1/M2 macrophages polarization on PAMs challenged by A1/A2. Interestingly, our results showed that A1 potently repolarizes macrophages into M1 macrophages compared to macrophages challenged with A2, as indicated by significant upregulation of pro-inflammatory genes (TNF- $\alpha, I L-6$ and $I L-12$ ) in PAMs challenged with A1 (Figure 2a). In contrast, A2 induction significantly up-regulates the anti-inflammatory gene Arg-1. Moreover, data from next-generation sequencing (NGS) supported our gene profiling results. They revealed that some pro-inflammatory genes were upregulated in PAMs challenged with A1 compared to A2 (Figure 3a,b). These genes include Nf-k $\beta, N N T, N F A T 5, P I 3 K C B$, 
and JARID2. Nuclear factor- $\kappa \beta$ (Nf-k $\beta$ ) synthesizes cytokines, such as TNF- $\alpha$, IL-1 $\beta, I L-6$, and IL-8, and thereby regulates pro-inflammatory genes [57]. The other pro-inflammatory genes, nuclear factor of activated T-cells 5 (NFAT5), enhance pro-inflammatory macrophage polarization when appropriately stimulated and would be neutralized in a pro-M2 tumor microenvironment [58-60]. Taken together, the NGS reported the shared genes involved in regulating signaling pathway. Additionally, we found that the T-cells receptor (TCR) signaling pathway were up-regulated (Figure 3d). A study demonstrated that the strength of TCR signaling guides the development of $\mathrm{CD} 8^{+} \mathrm{T}$-cells in the thymus, a process that may have a direct impact on autoimmune diseases [61]. In cooperation with cytokine signaling pathways, co-stimulatory molecules, chemokines, integrins and metabolites, TCR signaling drives the differentiation of activated T-cells into specific T-cell subtypes, namely Thelper type 1 (Th1), Th2, Th17, follicular T helper and regulatory T-cells (Treg) [62].

In order to investigate the relevance of the different sets of genes, we created the KEGG Pathway Enrichment Analysis. Our analysis showed the enrichment of a total of 19 KEGG and 4 KEGG pathways in 50 up- and down-regulated genes in A1-challenged PAMs compared to their counterpart challenged by A2 (Figures 4 and 5). KEGG pathway enrichment analysis revealed that the repressor activator protein 1 (Rap1) pathway is one of the most highlighted pathways and is modulated by TCR activation, supporting our previous finding from NGS. Rap1 plays a critical role in modulating T-cell responses and regulates interactions between T-cells and antigen-presenting cells (APCs). In one study, antigen-dependent Rap1 activation was shown to enhance T-cell-APC interactions and trigger activation-induced cell death (AICD) [63]. Additionally, the down-regulation of antiinflammatory genes has significant correlation with estrogen signaling pathway. Estrogen functions as a key regulator of anti-inflammatory responses and stimulates alternative macrophages polarization during cutaneous repair [64]. These results strongly suggest that A1 promotes the repolarization of PAMs toward M1 and can regulate the activation of Th1 cells through the secretion of pro-inflammatory cytokines.

The defenses of the innate immune system depend on three complement pathways in triggering a localized inflammatory response (which are the classical pathway, the alternative or properdin pathway, and the lectin pathway) to initiate a localized inflammatory response. Activation of the lectin pathway was not dependent on antibodies and is caused by the attachment of plasma mannose-binding lectin (MBL) to microbes [65]. In line with the reference, we found that C-type lectin receptors (CLRs) pathway was enriched in A1-challenged PAMs. CLRs signaling could be one of the targets for vaccine development. Signaling pathways induced by CLRs have the potential to directly activate the transcription factor NF-KB. Recognition of CLRs leads to several properties that are important for vaccine design, including pathogen internalization, degradation, and subsequent antigen presentation [66].

We then tested the effect of recombinant antigens on Th1 cells activation. We used a T-cell co-culture system for the experiments, and the results showed that A1 promoted Th1 activation by secretion of IFN- $\gamma$ cytokines (Figure $6 \mathrm{~b}$ ). Our results are in agreement with the literature showing that the inflammatory process is dominated by IFN- $\gamma$-producing Th1 cells [67]. It is known that activated Th1 cells potentially secrete proinflammatory cytokines IL-2, IFN- $\gamma$ and lymphotoxin- $\alpha$ (LT, TNF- $\beta$ ), and enhance B-cells maturation and the production of IgG2a antibody that optimize clearance of viruses and extracellular bacteria [29]. Moreover, Th1 cells are involved in cell-mediated immunity (CMI) by inhibiting infections through induction of complement fixation, opsonizing antibodies, and antibodies involved in antibody-dependent cell cytotoxicity, such as IgG1 in humans and IgG2a in mice [68]. CMI is clearly one of the most important regulators in PRRSV infection [69]. Gujer et al., 2011, [70] determined that IFN- $\gamma$ secreted by human plasmacytoid dendritic cells (PDCs) stimulate B-cells proliferation and differentiation to antibody-secreting cells by enhancing the interactions of B-cells and T-cells. Surprisingly, the pro-inflammatory gene profile of TNF- $\alpha$ was boosted up to 80-fold after A1-induced PAMs interacted with Th1 cells when we compared it with A1-induced PAMs alone in the mono cell culture system 
(only 15-fold) (Figure 6e). In combination of IFN- $\gamma$ secretion, these results proved that Th1 cell activation was triggered by cell-cell interaction of A1-induced PAMs and T cells. In addition, the expression of $I L-6$ was also significantly increased after being challenged with A1 compared to the control and A2 groups (Figure 6d). It is noteworthy that IL-6 binds to the receptors (CD126 and CD130) to regulate B-cells proliferation [71]. Furthermore, our results indicate that $\mathrm{A} 1 \mathrm{might}$ regulate the Th1 type response through the interaction of the Caspase-1 (Casp1) and interleukin 18 (IL-18) proteins. Pro-inflammatory cytokine IL-18 has the potent ability to support Th1 activation, but not Th1 development, and secrete IFN- $\gamma$ in the presence of $I L-12$ [72]. Indirectly, the up-regulated gene sets promote the interaction of inhibitor of the nuclear factor kappa B kinase subunit B (IKBKB or IKK $\beta$ ) protein, thus promote B-cells differentiation. IKK $\beta$ is considered to be a key factor of antibody-mediated immunity that provides an essential role in the activation of B-cells and the maintenance of B-cell survival, and IKK $\beta$ knockdown significantly induce cell death in all peripheral B-cell [73]. Besides, we described that the down-regulated genes in PAMs challenged by A1 possibly inhibits the interaction of ISG15 and USP18 as negative regulators of the immune response. High levels of free ISG15 were confirmed to be released by M2 macrophages and exert pro-tumor activity in pancreatic ductal adenocarcinoma (PDAC) by regulating PD-L1 expression [74]. By directly inhibiting type I IFN receptor signaling and regulating the expression program cell death-1, Usp18 has been shown to function as a negative regulator of innate anti-viral responses [75].

The question was, unlike A1, why A2 did not provoke Th1 response. One possible explanation for it was that $\mathrm{A} 2$ was engineered with lipidated recombinant protein that provides support only for B-cells activation as a humoral immune response, while A1 was engineered with T-cell epitopes that promote cell-mediated immune response. Tcell-inducing vaccines have been developed to induce $\mathrm{CD} 4^{+}$and $/$or $\mathrm{CD} 8^{+}$cells to give a protective adaptive immune response against viral infection. Recent clinical trials have now reported the strong protective effect of T-cell-inducing vaccines against a range of diseases, including HIV, malaria, influenza, tuberculosis, and cancer [76]. On the contrary, vaccination of mice with lipidated pneumococcal lipoproteins enhanced antibody-mediated immunity compared with vaccination with non-lipidated proteins, but had no significant effect on the CMI responses [77]. Another possibility is caused by ORF7, which is involved in A2. Conceivably, it is possible that ORF7 should play an essential role in inhibiting the cell-mediated immune response in PAMs against PRRSV. As described in a previous study, a robust T-cell response was induced by the PRRSV ORF6 (M) protein, whereas the PRRSV ORF7 protein induced a weak ability to stimulate T-cells [78]. Similarly, the neutralizing antibodies were not generated by antibodies directed against ORF7, although this is the most abundant and used for serological tests $[79,80]$. Another study compared the two vaccines developed, namely the PRRSV-ORF7 DNA vaccine (phCMV-ORF7) alone and PRRSV-ORF7 with IL-2 as an adjuvant. The results showed that PRRSV-ORF7 DNA vaccine (phCMV-ORF7) alone was insufficient to induce protective immunity, but had a positive inductive effect on activating vaccine-induced virus-specific cellular immunity when IL2 was added [81]. However, the role of cell-mediated immunity to ORF7 in protection against PRRSV is still controversial. Finally, we conclude that PRRSV-2 recombinant protein antigen A1 was more potent than A2 in protecting PRRSV infection by inducing repolarization of M1 macrophages and suppressing CD163 receptor expression for virus entry. Similarly, PRRSV-2 recombinant antigen A1 enhances the immune response by stimulating endogenous genes to activate the Th1 type immune response, and potentially facilitates B-cells proliferation and differentiation into antibody-secreting cells. Overall, our new findings could be useful for the development of screening new vaccine candidates against PRRSV. In addition, future studies including immunization and humoral immune response analyses are needed for a better understanding of long-lasting protection and the development of a potential vaccine against PRRSV. 


\section{Conclusions}

Based on the results of our study, recombinant PRRSV-2 antigen A1, which consists of the complete sequence of ORF5, a partial sequence of ORF6, and T-cell epitopes, can stimulate the repolarization of M2 PAMs to M1. These repolarized M1 PAMs decreased the total expression of CD163 for PRRSV entry, and hence offer a broad protection for both PRRSV-1 and PRRSV-2 strains infection. Cell-cell interaction of A1-induced PAMs and $\mathrm{T}$ cells can further stimulate Th1 response, along with the activation of $\mathrm{T}$ cell receptor signaling pathway in PAMs and the secretion of IFN- $\gamma$ from T cells, respectively. These results also suggest that macrophages are not only host target cells but also play a key role in immunomodulation during PRRSV infections. In addition to humoral immunity, our assays provide a vision to screening the antigenicity of novel subunit-protein vaccine candidates for their innate and T-cells-mediated immunity.

Supplementary Materials: The following data are available online at https://www.mdpi.com/ article/10.3390/vaccines9091009/s1. Figure S1: Production of recombinant g6Ld10T protein (A1) in baculovirus system. Schematic representation of the g6Ld10T transfer vector construct; Figure S2: Production of recombinant lipo-M5Nt protein (A2) in E. coli. Schematic representation of the lipoM5Nt transfer vector construct; Figure S3: Transcriptomic analysis of the differential genes between the groups.

Author Contributions: Conceptualization, K.-T.C. and H.-C.C.; methodology, R.W., Y.-S.L. and M.L.W.; software, R.W., Y.-S.L., M.-L.W., W.-B.C. and H.-W.C.; validation, R.W., Y.-S.L. and K.-T.C.; formal analysis, R.W., Y.-S.L., H.-W.C. and W.-B.C.; investigation, R.W., Y.-S.L., K.-T.C. and H.-C.C.; resources, K.-T.C. and H.-C.C.; data curation, K.-T.C. and H.-C.C.; writing-original draft preparation, R.W., Y.-S.L., K.-T.C. and H.-C.C.; writing-review and editing, R.W., Y.-S.L., K.-T.C. and H.-C.C.; visualization, R.W. and Y.-S.L.; supervision, K.-T.C. and H.-C.C.; project administration, K.-T.C. and H.-C.C.; funding acquisition, K.-T.C. and H.-C.C. All authors have read and agreed to the published version of the manuscript.

Funding: This research received no external funding.

Institutional Review Board Statement: The study was approved by the Institutional Animal Care and Use Committee (IACUC) of Veterinary Medicine at National Pingtung University of Science and Technology (NPUST), Taiwan.

Informed Consent Statement: Not applicable.

Data Availability Statement: Data are contained within the article. Reported results can be found in Supplementary Materials.

Acknowledgments: This study was financially supported by the Research Center for Animal Biologics, from The Featured Areas Research Center Program within the framework of the Higher Education Sprout Project by the Ministry of Education and the Ministry of Science and Technology (MOST 107-3017-F-020-001-, MOST 108-3017-F-020 -001-, MOST 109-2634-F-020-001-, MOST 110-2634-F-020-001-, MOST 109-2314-B-020-002, MOST 110-2314-B-020-003), Taiwan.

Conflicts of Interest: The authors declare no conflict of interest.

\section{References}

1. Brinton, M.; Gulyaeva, A.; Balasuriya, U.; Dunowska, M.; Faaberg, K.S.; Goldberg, T.; Leung, F.C.C.; Nauwynck, H.J.; Snijder, E.J.; Stadejek, T.; et al. ICTV Virus Taxonomy Profile: Arteriviridae. J. Gen. Virol. 2021, 102, 001632. [CrossRef]

2. Li, X.; Galliher-Beckley, A.; Pappan, L.; Trible, B.; Kerrigan, M.; Beck, A.; Hesse, R.; Blecha, F.; Nietfeld, J.C.; Rowland, R.R.; et al. Comparison of host immune responses to homologous and heterologous type II porcine reproductive and respiratory syndrome virus (PRRSV) challenge in vaccinated and unvaccinated pigs. BioMed Res. Int. 2014, 2014, 416727. [CrossRef]

3. Wissink, E.H.; Kroese, M.V.; Van Wijk, H.A.; Rijsewijk, F.A.; Meulenberg, J.J; Rottier, P.J. Envelope protein requirements for the assembly of infectious virions of porcine reproductive and respiratory syndrome virus. J. Virol. 2005, 79, 12495-12506. [CrossRef] [PubMed]

4. Durán, M.G.; Costa, S.; Sarraseca, J.; de la Roja, N.; García, J.; García, I.; Rodríguez, M.J. Generation of porcine reproductive and respiratory syndrome (PRRS) virus-like-particles (VLPs) with different protein composition. J. Virol. Methods 2016, 236, 77-86. [CrossRef] [PubMed] 
5. $\quad$ Pesente, P.; Rebonato, V.; Sandri, G.; Giovanardi, D.; Ruffoni, L.S.; Torriani, S. Phylogenetic analysis of ORF5 and ORF7 sequences of porcine reproductive and respiratory syndrome virus (PRRSV) from PRRS-positive Italian farms: A showcase for PRRSV epidemiology and its consequences on farm management. Vet. Microbiol. 2006, 114, 214-224. [CrossRef] [PubMed]

6. Kang, H.; Yu, J.E.; Shin, J.E.; Kang, A.; Kim, W.I.; Lee, C.; Lee, J.; Cho, I.S.; Choe, S.E.; Cha, S.H. Geographic distribution and molecular analysis of porcine reproductive and respiratory syndrome viruses circulating in swine farms in the Republic of Korea between 2013 and 2016. BMC Vet. Res. 2018, 14, 160. [CrossRef] [PubMed]

7. Crisci, E.; Fraile, L.; Montoya, M. Cellular innate immunity against PRRSV and swine influenza viruses. Vet. Sci. 2019, 6, 26. [CrossRef] [PubMed]

8. Das, P.B.; Dinh, P.X.; Ansari, I.H.; De Lima, M.; Osorio, F.A.; Pattnaik, A.K. The minor envelope glycoproteins GP2a and GP4 of porcine reproductive and respiratory syndrome virus interact with the receptor CD163. J. Virol. 2010, 84, 1731-1740. [CrossRef]

9. Kappes, M.A.; Faaberg, K.S. PRRSV structure, replication and recombination: Origin of phenotype and genotype diversity. Virology 2015, 479, 475-486. [CrossRef]

10. Zhang, Q.; Yoo, D. PRRS virus receptors and their role for pathogenesis. Vet. Microbiol. 2015, 177, 229-241. [CrossRef]

11. Fang, L.; Jiang, Y.; Xiao, S.; Niu, C.; Zhang, H.; Chen, H. Enhanced immunogenicity of the modified GP5 of porcine reproductive and respiratory syndrome virus. Virus Genes 2006, 32, 5-11. [CrossRef] [PubMed]

12. Wang, X.; Li, J.; Jiang, P.; Li, Y.; Zeshan, B.; Cao, J.; Wang, X. GM-CSF fused with GP3 and GP5 of porcine reproductive and respiratory syndrome virus increased the immune responses and protective efficacy against virulent PRRSV challenge. Virus Res. 2009, 143, 24-32. [CrossRef]

13. Lewinsohn, D.A.; Lewinsohn, D.M.; Scriba, T.J. Polyfunctional CD4 ${ }^{+}$T-cells as targets for tuberculosis vaccination. Front. Immunol. 2017, 8, 1262. [CrossRef]

14. Wei, C.; Dai, A.; Fan, J.; Li, Y.; Chen, A.; Zhou, X.; Luo, M.; Yang, X.; Liu, J. Efficacy of Type 2 PRRSV vaccine against challenge with the Chinese lineage 1 (NADC30-like) PRRSVs in pigs. Sci. Rep. 2019, 9, 10781. [CrossRef] [PubMed]

15. Meng, X.J. Heterogeneity of porcine reproductive and respiratory syndrome virus: Implications for current vaccine efficacy and future vaccine development. Vet. Microbiol. 2000, 74, 309-329. [CrossRef]

16. Mengeling, W.L.; Lager, K.M.; Vorwald, A.C.; Koehler, K.J. Strain specificity of the immune response of pigs following vaccination with various strains of porcine reproductive and respiratory syndrome virus. Vet. Microbiol. 2003, 93, 13-24. [CrossRef]

17. Opriessnig, T.; Halbur, P.G.; Yoon, K.J.; Pogranichniy, R.M.; Harmon, K.M.; Evans, R.; Key, K.F.; Pallares, F.J.; Thomas, P.; Meng, X.J. Comparison of molecular and biological characteristics of a modified live porcine reproductive and respiratory syndrome virus (PRRSV) vaccine (ingelvac PRRS MLV), the parent strain of the vaccine (ATCC VR2332), ATCC VR2385, and two recent field isolates of PRRSV. J. Virol. 2002, 76, 11837-11844.

18. Nascimento, I.P.; Leite, L.C. Recombinant vaccines and the development of new vaccine strategies. Braz. J. Med. Biol. Res. 2012, 45, 1102-1111. [CrossRef]

19. Clem, A.S. Fundamentals of vaccine immunology. J. Glob. Infect. Dis. 2011, 3, 73. [CrossRef] [PubMed]

20. Salerno-Gonçalves, R.; Sztein, M.B. Cell-mediated immunity and the challenges for vaccine development. Trends Microbiol. 2006, 14, 536-542. [CrossRef]

21. Wang, T.Y.; Liu, Y.G.; Li, L.; Wang, G.; Wang, H.M.; Zhang, H.L.; Zhao, S.F.; Gao, J.C.; An, T.Q.; Tian, Z.J.; et al. Porcine alveolar macrophage CD163 abundance is a pivotal switch for porcine reproductive and respiratory syndrome virus infection. Oncotarget 2018, 9, 12174. [CrossRef] [PubMed]

22. Ezquerra, A.; Revilla, C.; Alvarez, B.; Perez, C.; Alonso, F.; Dominguez, J. Porcine myelomonocytic markers and cell populations. Dev. Comp. Immunol. 2009, 33, 284-298. [CrossRef]

23. Calvert, J.G.; Slade, D.E.; Shields, S.L.; Jolie, R.; Mannan, R.M.; Ankenbauer, R.G.; Welch, S.K.W. CD163 expression confers susceptibility to porcine reproductive and respiratory syndrome viruses. J. Virol. 2007, 81, 7371-7379. [CrossRef] [PubMed]

24. Hu, J.M.; Liu, K.; Liu, J.H.; Jiang, X.L.; Wang, X.L.; Chen, Y.Z.; Li, S.G.; Zou, H.; Pang, L.J.; Liu, C.X.; et al. CD163 as a marker of M2 macrophage, contribute to predict aggressiveness and prognosis of Kazakh esophageal squamous cell carcinoma. Oncotarget 2017, 8, 21526. [CrossRef] [PubMed]

25. Veloso, P.; Fernández, A.; Terraza-Aguirre, C.; Álvarez, C.; Vernal, R.; Escobar, A.; Hernández, M. Macrophages skew towards M1 profile through reduced CD163 expression in symptomatic apical periodontitis. Clin. Oral Investig. 2020, 24, 4571-4581. [CrossRef] [PubMed]

26. Alvarado-Vazquez, P.A.; Bernal, L.; Paige, C.A.; Grosick, R.L.; Vilrriales, C.M.; Ferreira, D.W.; Ulecia-Morón, C.; Romero-Sandoval, E.A. Macrophage-specific nanotechnology-driven CD163 overexpression in human macrophages results in an M2 phenotype under inflammatory conditions. Immunobiology 2017, 222, 900-912. [CrossRef]

27. Wang, L.; Hu, S.; Liu, Q.; Li, Y.; Xu, L.; Zhang, Z.; Cai, X.; He, X. Porcine alveolar macrophage polarization is involved in inhibition of porcine reproductive and respiratory syndrome virus (PRRSV) replication. J. Vet. Med. Sci. 2017, 79, 1906-1915. [CrossRef]

28. Han, Q.; Shi, H.; Liu, F. CD163 ${ }^{+}$M2-type tumor-associated macrophage support the suppression of tumor-infiltrating T-cells in osteosarcoma. Int. Immunopharmacol. 2016, 34, 101-106. [CrossRef]

29. Muraille, E.; Leo, O.; Moser, M. TH1/TH2 paradigm extended: Macrophage polarization as an unappreciated pathogen-driven escape mechanism? Front. Immunol. 2014, 5, 603. [CrossRef]

30. Shannon, A.; Carty, G.A.K. T-Cell Immunity. In Hematology; Elsevier: Amsterdam, The Netherlands, 2018; pp. 221-239. [CrossRef] 
31. Nygard, A.B.; Jørgensen, C.B.; Cirera, S.; Fredholm, M. Selection of reference genes for gene expression studies in pig tissues using SYBR green qPCR. BMC Mol. Biol. 2007, 8, 1-6. [CrossRef]

32. Livak, K.J.; Schmittgen, T.D. Analysis of relative gene expression data using real-time quantitative PCR and the $2^{-\Delta \Delta C T}$ method. Methods 2001, 25, 402-408. [CrossRef]

33. Bolger, A.M.; Lohse, M.; Usadel, B. Trimmomatic: A flexible trimmer for Illumina Sequence Data. "Trimmomatic v0.36": Read quality filtering \& adapter trimming. Bioinformatics 2014, 30, 2114-2120.

34. Langmead, B.; Salzberg, S.L. Fast gapped-read alignment with Bowtie 2. Nat. Methods 2012, 9, 357-359. [CrossRef] [PubMed]

35. Li, B.; Dewey, C.N. RSEM: Accurate transcript quantification from RNA-Seq data with or without a reference genome. BMC Bioinform. 2011, 12, 323. [CrossRef] [PubMed]

36. Ashburner, M.; Ball, C.A.; Blake, J.; Botstein, D.; Butler, H.; Cherry, J.M.; Davis, A.P.; Dolinski, K.; Dwight, S.S.; Eppig, J.T.; et al. Gene ontology: Tool for the unification of biology. The Gene Ontology Consortium. Nat. Genet. 2000, 25, 25-29. [CrossRef] [PubMed]

37. Kanehisa, M.; Goto, S. KEGG: Kyoto Encyclopedia of Genes and Genomes. Nucleic Acids Res. 2000, 28, 27-30. [CrossRef]

38. Sánchez, E.G.; Riera, E.; Nogal, M.; Gallardo, C.; Fernández, P.; Bello-Morales, R.; López-Guerrero, J.A.; Chitko-McKown, C.G.; Richt, J.A.; Revilla, Y. Phenotyping and susceptibility of established porcine cells lines to African Swine Fever Virus infection and viral production. Sci. Rep. 2017, 7, 10369. [CrossRef]

39. Rodríguez-Gómez, I.M.; Sánchez-Carvajal, J.M.; Pallarés, F.J.; Mateu, E.; Carrasco, L.; Gómez-Laguna, J. Virulent Lena strain induced an earlier and stronger downregulation of CD163 in bronchoalveolar lavage cells. Vet. Microbiol. 2019, 235, 101-109. [CrossRef] [PubMed]

40. Van Gucht, S.; Labarque, G.; Van Reeth, K. The combination of PRRS virus and bacterial endotoxin as a model for multifactorial respiratory disease in pigs. Vet. Immunol. Immunopathol. 2004, 102, 165-178. [CrossRef]

41. Novakovic, P.; Harding, J.C.; Ladinig, A.; Al-Dissi, A.N.; MacPhee, D.J.; Detmer, S.E. Relationships of CD163 and CD169 positive cell numbers in the endometrium and fetal placenta with type 2 PRRSV RNA concentration in fetal thymus. Vet. Res. 2016, $47,76$. [CrossRef]

42. Secombes, C.J.; Wang, T. The innate and adaptive immune system of fish. In Infectious Disease in Aquaculture; Woodhead Publishing: Shaxton, UK, 2012; pp. 3-68.

43. Schmidt, A.; Oberle, N.; Krammer, P.H. Molecular mechanisms of Treg-mediated T-cell suppression. Front. Immunol. $2012,3,51$. [CrossRef] [PubMed]

44. Cox, M.M. Development of an Influenza Virus Vaccine Using the Baculovirus-Insect Cell Expression System: Implications for Pandemic Preparedness. 2009. Available online: https: / / edepot.wur.nl/14323 (accessed on 7 May 2021).

45. Tripathi, N.K.; Shrivastava, A. Recent developments in bioprocessing of recombinant proteins: Expression hosts and process development. Front. Bioeng. Biotechnol. 2019, 7, 420. [CrossRef]

46. Rayees, S.; Rochford, I.; Joshi, J.C.; Joshi, B.; Banerjee, S.; Mehta, D. Macrophage TLR4 and PAR2 signaling: Role in regulating vascular inflammatory injury and repair. Front. Immunol. 2020, 11, 2091. [CrossRef] [PubMed]

47. Han, K.; Seo, H.W.; Park, C.; Chae, C. Vaccination of sows against type 2 Porcine Reproductive and Respiratory Syndrome Virus (PRRSV) before artificial insemination protects against type 2 PRRSV challenge but does not protect against type 1 PRRSV challenge in late gestation. Vet. Res. 2014, 45, 12. [CrossRef]

48. Chen, N.; Trible, B.R.; Kerrigan, M.A.; Tian, K.; Rowland, R.R. ORF5 of porcine reproductive and respiratory syndrome virus (PRRSV) is a target of diversifying selection as infection progresses from acute infection to virus rebound. Infect. Genet. Evol. 2016, 40, 167-175. [CrossRef] [PubMed]

49. Sewell, H.F.; Agius, R.M.; Kendrick, D.; Stewart, M. COVID-19 Vaccines: Delivering Protective Immunity. BMJ 2020, 371 , m4838. [CrossRef] [PubMed]

50. Nazimek, K.; Ptak, W.; Nowak, B.; Ptak, M.; Askenase, P.W.; Bryniarski, K. Macrophages play an essential role in antigen-specific immune suppression mediated by $\mathrm{T} \mathrm{CD}^{+}$cell-derived exosomes. Immunology 2015, 146, 23-32. [CrossRef]

51. Mills, C. M1 and M2 macrophages: Oracles of health and disease. Crit. Rev. Immunol. 2012, 32, 463-488. [CrossRef]

52. Mills, C.D.; Lenz, L.L.; Harris, R. A breakthrough: Macrophages-directed cancer immunotherapy. Cancer Res. 2016, 76, 513-516. [CrossRef] [PubMed]

53. Sica, A.; Mantovani, A. Macrophage plasticity and polarization: In vivo veritas. J. Clin. Investig. 2012, 122, 787-795. [CrossRef] [PubMed]

54. Lee, K.Y. M1 and M2 polarization of macrophages: A mini-review. Med. Biol. Sci. Eng. 2019, 2, 1-5. [CrossRef]

55. Yao, Y.; Xu, X.H.; Jin, L. Macrophage polarization in physiological and pathological pregnancy. Front. Immunol. $2019,10,792$. [CrossRef] [PubMed]

56. Zhu, Z.; Zhang, H.; Zhang, X.; He, S.; Dong, W.; Wang, X.; Chen, Y.; Liu, X.; Guo, C. Lipopolysaccharide downregulates CD163 expression to inhibit PRRSV infection via TLR4-NF-kB pathway. Front. Microbiol. 2020, 11, 501. [CrossRef] [PubMed]

57. Tak, P.P.; Firestein, G.S. NF-kB: A key role in inflammatory diseases. J. Clin. Investig. 2001, 107, 7-11. [CrossRef] [PubMed]

58. Aramburu, J.; López-Rodríguez, C. Regulation of inflammatory functions of macrophages and T lymphocytes by NFAT5. Front. Immunol. 2019, 10, 535. [CrossRef] [PubMed] 
59. Buxadé, M.; Lunazzi, G.; Minguillón, J.; Iborra, S.; Berga-Bolaños, R.; Del Val, M.; Aramburu, J.; López-Rodríguez, C. Gene expression induced by Toll-like receptors in macrophages requires the transcription factor NFAT5. J. Exp. Med. 2012, 209, 379-393. [CrossRef] [PubMed]

60. Tellechea, M.; Buxadé, M.; Tejedor, S.; Aramburu, J.; López-Rodríguez, C. NFAT5-regulated macrophage polarization supports the proinflammatory function of macrophages and T lymphocytes. J. Immunol. 2018, 200, 305-315. [CrossRef]

61. Conley, J.M.; Gallagher, M.P.; Berg, L.J. T-cells and gene regulation: The switching on and turning up of genes after T-cell receptor stimulation in CD8 T-cells. Front. Immunol. 2016, 7, 76. [CrossRef]

62. Park, S.G.; Hwang, J.R.; Byeon, Y.; Kim, D. Recent insights of T-cell receptor-mediated signaling pathways for T-cell activation and development. Exp. Mol. Med. 2020, 52, 750-761.

63. Katagiri, K.; Hattori, M.; Minato, N.; Kinashi, T. Rap1 functions as a key regulator of T-cell and antigen-presenting cell interactions and modulates T-cell responses. Mol. Cell. Biol. 2002, 22, 1001-1015. [CrossRef] [PubMed]

64. Campbell, L.; Emmerson, E.; Williams, H.; Saville, C.R.; Krust, A.; Chambon, P.; Mace, K.A.; Hardman, M.J. Estrogen receptoralpha promotes alternative macrophage activation during cutaneous repair. J. Investig. Dermatol. 2014, 134, 2447-2457. [CrossRef]

65. Noris, M.; Remuzzi, G. Overview of complement activation and regulation. In Seminars in Nephrology; WB Saunders: Milan, Italy, 2013; Volume 33, pp. 479-492.

66. Geijtenbeek, T.B.; Gringhuis, S.I. Signalling through C-type lectin receptors: Shaping immune responses. Nat. Rev. Immunol. 2009, 9, 465-479. [CrossRef]

67. Furiati, S.C.; Catarino, J.S.; Silva, M.V.; Silva, R.F.; Estevam, R.B.; Teodoro, R.B.; Pereira, S.L.; Ataide, M.; Rodrigues, V.; Rodrigues, D.B. Th1, Th17, and treg responses are differently modulated by TNF- $\alpha$ inhibitors and methotrexate in psoriasis patients. Sci. Rep. 2019, 9, 7526. [CrossRef]

68. Skapenko, A.; Leipe, J.; Lipsky, P.E.; Schulze-Koops, H. The role of the T-cell in autoimmune inflammation. Arthritis Res. Ther. 2005, 7, S4-S14. [CrossRef] [PubMed]

69. Parida, R. Cell-Mediated Immunity in Porcine Reproductive and Respiratory Syndrome Virus. 2012. Available online: https: / / digitalcommons.unl.edu/vetscidiss (accessed on 27 May 2021).

70. Gujer, C.; Sandgren, K.J.; Douagi, I.; Adams, W.C.; Sundling, C.; Smed-Sörensen, A.; Seder, R.A.; Hedestam, G.B.; Loré, K. IFN- $\alpha$ roduced by human plasmacytoid dendritic cells enhances T-cell-dependent naïve B cell differentiation. J. Leukoc. Biol. 2011, 89, 811-821. [CrossRef] [PubMed]

71. Friederichs, K.; Schmitz, J.; Weissenbach, M.; Heinrich, P.C.; Schaper, F. Interleukin-6-induced proliferation of pre-B cells mediated by receptor complexes lacking the SHP2/SOCS3 recruitment sites revisited. Eur. J. Biochem. 2001, 268, 6401-6407. [CrossRef]

72. Nakanishi, K. Unique action of interleukin-18 on T-cells and other immune cells. Front. Immunol. 2018, 9, 763. [CrossRef]

73. Li, Z.W.; Omori, S.A.; Labuda, T.; Karin, M.; Rickert, R.C. IKK $\beta$ is required for peripheral B cell survival and proliferation. J. Immunol. 2003, 170, 4630-4637. [CrossRef] [PubMed]

74. Burks, J.; Fleury, A.; Livingston, S.; Smith, J.P. ISG15 pathway knockdown reverses pancreatic cancer cell transformation and decreases murine pancreatic tumor growth via downregulation of PDL-1 expression. Cancer Immunol. Immunother. 2019, 68, 2029-2039. [CrossRef]

75. Wood, L.; Mavinkurve, V.; Muthukumaran, G.; Malo, D.; Paterson, Y. USP18 as a novel regulator of PD-1 and IFNAR1-mediated immune dysfunction. J. Immunol. 2015, 194, 629.

76. Gilbert, S.C. T-cell-inducing vaccines-What's the future. Immunology 2012, 135, 19-26. [CrossRef] [PubMed]

77. Voß, F.; van Beek, L.F.; Schwudke, D.; Ederveen, T.H.; van Opzeeland, F.J.; Thalheim, D.; Werner, S.; de Jonge, M.I.; Hammerschmidt, S. Lipidation of Pneumococcal Antigens Leads to Improved Immunogenicity and Protection. Vaccines 2020, 8, 310. [CrossRef]

78. Han, Y.W.; Kim, S.B.; Rahman, M.; Uyangaa, E.; Lee, B.M.; Kim, J.H.; Park, K.I.; Hong, J.T.; Han, S.B.; Eo, S.K. Systemic and mucosal immunity induced by attenuated Salmonella enterica serovar Typhimurium expressing ORF7 of porcine reproductive and respiratory syndrome virus. Comp. Immunol. Microbiol. Infect. Dis. 2011, 34, 335-345. [CrossRef] [PubMed]

79. Murtaugh, M.P. PRRS immunology: What are we missing. Proc. AASV 2004, 359, 367.

80. Kimman, T.G.; Cornelissen, L.A.; Moormann, R.J.; Rebel, J.M.; Stockhofe-Zurwieden, N. Challenges for porcine reproductive and respiratory syndrome virus (PRRSV) vaccinology. Vaccine 2009, 27, 3704-3718. [CrossRef]

81. Rompato, G.; Ling, E.; Chen, Z.; Van Kruiningen, H.; Garmendia, A.E. Positive inductive effect of IL-2 on virus-specific cellular responses elicited by a PRRSV-ORF7 DNA vaccine in swine. Vet. Immunol. Immunopathol. 2006, 109, 151-160. [CrossRef] [PubMed] 